\title{
The cellular microenvironment modulates the role of PAI-1 and vitronectin in mediating cell-matrix interactions
}

\author{
Sumit Goswami, Lawrence C. Thompson, Lindsay Wickman, Cynthia B. Peterson
}

The Department of Biochemistry and Cellular and Molecular Biology, The University of Tennessee, Knoxville, USA

Email: cbpeters@utk.edu

Received 25 October 2012; revised 26 November 2012; accepted 2 December 2012

\begin{abstract}
Plasminogen activator inhibitor-1 (PAI-1), a member of the serine protease inhibitor (serpin) superfamily of proteins, circulates in a complex with vitronectin. Furthermore, these two proteins are co-localized in the extracellular matrix (ECM) in many different pathophysiological conditions. Though PAI-1 is a well-characterized inhibitor of serine proteases, recent emphasis has also focused on its protease-independent functions. Vitronectin, a multi-domain protein that binds a wide variety of ligands and proteins, exists in the circulation in a preferred monomeric state, while in the extracellular matrix it exists as a multimer resulting from an altered conformation. Though the mechanism for the conformational alterations and compartmentalization in tissues is unknown, there are a number of biomolecules including PAI-1 that appear to cause such changes. Experimental analysis has established that PAI-1 induces association of vitronectin to higher-order species in a concentration-dependent fashion [1]. This report extends our investigations into the mechanism of the interaction between vitronectin and PAI-1 to explore the physiological relevance of these higher-order complexes for cellular adhesion and migration. In this study, we evaluate the effects of the pericellular microenvironment on the functions of the multimeric complexes in a variety of relevant biological settings. Our findings underscore the importance of the variability of components within this microenvironment, including different receptors and ECM components, in governing the way in which the vitronectin/PAI-1 complex mediates cell-matrix interactions.
\end{abstract}

Keywords: PAI-1; Vitronectin; Extracellular Matrix; Receptors

\section{INTRODUCTION}

Vitronectin is a glycoprotein that exists in both a cir- culating form and a tissue-associated form in the extracellular matrix (ECM), where these respective species participate in regulating hemostasis and cell binding and migration. In blood, vitronectin exists primarily in a monomeric form, whereas in the ECM it exists as a higherorder multimer [2-4]. While the exact mechanism for this conformational alteration, oligomerization and partitioning to different compartments in the body is unknown, vitronectin adopts specific and distinct functions in blood and the ECM. Such a versatile and multifunctional role for this protein arises from its binding to a wide variety of ligands, including the thrombin-antithrombin complex $[5,6]$, heparin [7-9], PAI-1 [10-12], complement proteins [13] and several cell surface receptors, including integrins and the urokinase plasminogen activator receptor (uPAR) [14-20]. Through these various interactions, vitronectin regulates many physiological and pathological processes in the realm of fibrinolysis, thrombosis, coagulation, wound healing, and cell adhesion and/or migration [21-23]. Regulation of cell adhesion and migration comes from its role as a matrix protein that mediates outside-in and inside-out signaling by binding to cell surface receptors, including UPAR and certain subclasses of integrins (primarily $\alpha \mathrm{v} \beta 3$ and $\alpha \mathrm{v} \beta 5$ ) [2,14,23-27].

PAI-1 is a binding partner for vitronectin and is a member of the serpin (serine protease inhibitor) family of proteins, acting as the primary inhibitor of urokinase plasminogen activator (uPA) and tissue plasminogen activator (tPA) [28]. Like vitronectin, PAI-1 is found in both the circulation and the ECM, where it regulates the formation of plasmin and contributes to the control of thrombolysis and pericellular proteolysis [29,30]. Such protease-dependent effects of PAI-1 have been recognized for a long while, although more recent work has highlighted ways in which PAI-1 functions in a proteaseindependent fashion. For example, a noteworthy protease-independent function of PAI-1 is the regulation of cell surface receptor interactions with ECM-associated vitronectin. PAI-I has been shown to physically interfere with the interaction of UPAR and integrin receptors with vitronectin, blocking UPAR mediated binding of vitro- 
nectin to U937 cells, endothelial cells and UPAR-transfected 293 cells [14,31]. PAI-1 also inhibits uPAR-mediated migration of U937 and melanoma cells on a substratum with multimeric "denatured" vitronectin [31,32] and blocks binding and migration of smooth muscle cells via vitronectin in a $\alpha \mathrm{v} \beta 3$ dependent manner [33]. Although evidence exists suggesting that PAI-1 is pro-angiogenic and pro-tumorigenic [34,35], other studies indicate that PAI-1 can inhibit angiogenesis [36] in a vitronectin-dependent fashion. Furthermore, McMahon et al. have demonstrated that PAI-1-mediated effects on tumor formation and angiogenesis are dose-dependent [37], with low concentrations of PAI-1 exhibiting proangiogenic effects and high concentrations acting in an anti-angiogenic manner [37]. A similar dose-dependent effect of PAI-1 on angiogenesis was observed in a study by Devy et al. [38] that suggested that the increase in angiogenesis observed at physiological concentrations of PAI-1 is independent of its interactions with vitronectin [38]. From these studies and others, significant controversy has arisen regarding how PAI-1 and vitronectin mediate cell-matrix interactions.

Though it appears that self-assembly of vitronectin to higher-order oligomers occurs in a biological setting [39], most in vitro studies have been performed with a "multimeric" form of vitronectin. Such multimeric forms of vitronectin have been denatured and renatured by heating or treatment with chaotropic agents to mimic the oligomeric matrix-associated form of vitronectin. Studies with antibodies indicate that this denatured/renatured multimeric vitronectin exhibits some of the conformational features observed with matrix-associated oligomeric vitronectin $[5,39]$, leading to an assumption that the "multimeric" form of vitronectin is similar to the naturally occurring matrix-associated oligomeric form of vitronectin. However, it is clear that oligomeric forms of vitronectin formed in vivo differ significantly from denatured/renatured protein in both structure and function. For example, Seiffert et al. found that platelet-associated multimeric vitronectin is structurally and conformationally distinct from "multimeric" vitronectin [40]. Their study indicated that platelet-released multimeric vitronectin was significantly smaller in size compared to denatured "multimeric" vitronectin, and that several conformationally sensitive epitopes were more reactive in "multimeric" vitronectin than platelet released vitronectin.

A number of biomolecules can initiate the process of self-assembly and oligomerization of vitronectin, including the T-AT complex, the terminal complement complex (C5b-C7) and PAI-1 [5,41,42]. In our studies, we have been deliberate in purifying monomeric vitronectin from blood in order to investigate its conversion to higherorder forms that associate with the ECM in the presence of PAI-1 [1]. We have confirmed that PAI-1 induces oligomerization of vitronectin in a concentration-dependent manner and have demonstrated that PAI-1 remains incorporated in this multimeric complex for several hours [1,43-45]. In this fashion, PAI-1 acts as a cofactor for the transformation of vitronectin into its matrix-associated form. The higher-order complexes formed by the interaction between these two proteins influence their functions in the ECM. In a number of pathophysiological situations PAI-1 is co-localized with vitronectin [46-48]. For example, in patients with membranous nephropathy PAI-1 is observed in association with vitronectin in the glomerular sub-epithelial tissue [46], and this interaction was proposed to perturb the fibrinolytic system within the glomeruli affected by the disease. Co-localization of vitronectin and PAI-1 in the extracellular space surrounding the sinusoidal cells of patients with hepatic fibrosis has been shown to influence the level of active transforming growth factor beta 1 [47]. Another noteworthy example is the co-localization of vitronectin and PAI-1 in the atherosclerotic arterial vessel wall [48], which is proposed to play a role in regulating thrombin activity. We hypothesize that higher-order complexes of vitronectin and PAI-1 modulate cell binding and migration and anticipate that effects of the complexes on cell-matrix interactions will be sensitive to the pericellular microenvironment comprised of variable matrix components and sets of receptors expressed on the cell surface in a cellspecific manner.

In this study, we compare and contrast monomeric vitronectin and higher-order complexes containing PAI-1 in mediating cell-matrix interactions. The overarching goal of this work is to build a comprehensive picture of the way that vitronectin/PAI-1 complexes modulate cell adhesion and migration by mediating simultaneous bidirectional interactions with ECM components and cellsurface receptors. Our approach has avoided the denaturation/renaturation process and has instead relied on using the oligomeric form of vitronectin that arises upon interaction with PAI-1. Also, we have controlled the variability of certain features within the microenvironment at the cell-matrix interface, constituted of different matrix molecules and the array of receptors that are expressed on the surface of particular cell types. We have limited our study to the primary components of the ECM, collagen-IV and HSPG, and two cell types, fibrosarcoma and endothelial cells. Also, we have tested specific growth factors in modulating receptor expression on the cell surface. Our results indicate that higher-order vitronectin/PAI-1 complexes exhibit enhanced binding to matrix components. In contrast to other reports in the literature, PAI-1 within these multimeric complexes does not disrupt binding to uPAR or integrins. Our results also demonstrate that the specific adhesion and migration ef- 
fects of PAI-1 within the higher-order complexes are dictated by the cellular microenvironment.

\section{MATERIALS AND METHODS}

Proteins and reagents: Recombinant PAI-1 and the Q123K variant were expressed in the E. coli Rosetta2(DE3)pLysS strain, grown in TB and induced at $15^{\circ} \mathrm{C}$. Purification was achieved in three steps, with cation exchange chromatography on SP-Sepharose, affinity chromatography by IMAC, and size exclusion chromatography using Sephacryl S-100 as described [49]. The correctly folded recombinant somatomedin-B (SMB) domain was expressed and purified by binding to an immobilized stable mutant of PAI-1 as performed by Thompson et al. [50]. HSPG was purchased from Sigma. Collagen IV was purchased from BD Biosciences. Recombinant integrins and antibodies specific for integrins were from Millipore Corporation. The 1E934 monoclonal antibody specific for vitronectin was obtained from Molecular Innovations. Recombinant uPAR and monoclonal antibodies directed against UPAR were purchased from $\mathrm{R}$ $\&$ D systems. Peroxidase conjugated anti-mouse IgG and anti-rabbit IgG were from Vector Labs, and Alexa-488 conjugated goat anti-mouse IgG was purchased from Invitrogen.

Purification of vitronectin: Monomeric vitronectin was purified from human plasma using a procedure adapted from Dahlback and Podack [51]. Barium chloride was added to $3 \mathrm{~L}$ of plasma and centrifuged, and $\left(\mathrm{NH}_{4}\right)_{2} \mathrm{SO}_{4}$ was added to the supernatant at $50 \%$ saturation. After an overnight incubation, the precipitate was harvested by centrifugation, resuspended in $1 \mathrm{~L}$ of phosphate buffer, pH 7.0, containing DTNB $\left(20 \mathrm{mM} \mathrm{NaH}{ }_{2} \mathrm{PO}_{4}, 0.1 \mathrm{mM}\right.$ EDTA, and $1 \mathrm{mM}$ DTNB) and centrifuged to clarify. The supernatant was dialyzed against $22 \mathrm{~L}$ of the same buffer without DTNB at $4^{\circ} \mathrm{C}$. Protein was then chromatographed on a DEAE Sephacel column $(5 \times 21.5 \mathrm{~cm})$ by elution with a linear $0-0.5 \mathrm{M} \mathrm{NaCl}$ gradient with a total volume of $4.4 \mathrm{~L}$. Pooled vitronectin-containing fractions from the DEAE column were chromatographed in two batches on a Blue-Sepharose column $(5 \times 17.5 \mathrm{~cm})$ using a linear gradient from $0.15-3.0 \mathrm{M} \mathrm{NaCl}$ with a total volume of $4.4 \mathrm{~L}$. Vitronectin-containing fractions were pooled and dialyzed against Tris buffer $(20 \mathrm{mM}$ Tris, $\mathrm{pH}$ 7.4 , containing $20 \mathrm{mM} \mathrm{NaCl}$ and $0.1 \mathrm{mM}$ EDTA) and chromatographed on a heparin-Sepharose column $(2.5 \times$ $15 \mathrm{~cm}$ ) eluted with a linear gradient from 0.02 to $1.0 \mathrm{M}$ $\mathrm{NaCl}$ in a total volume of $0.8 \mathrm{~L}$. The protein pool from the heparin column was concentrated by ultrafiltration to $\sim 8 \mathrm{~mL}$ and chromatographed in two aliquots on a highresolution Sephacryl S-200 gel filtration column $(2.5 \times$ $115 \mathrm{~cm})$ equilibrated in PBS $(10 \mathrm{mM}$ sodium phosphate, $1.8 \mathrm{mM}$ potassium phosphate, $137 \mathrm{mM} \mathrm{NaCl}, 2.7 \mathrm{mM}$ $\mathrm{KCl}, \mathrm{pH}$ 7.4). Three $\mathrm{ml}$ fractions were collected from the
Sephacryl S-200 gel filtration column at flow rate of 0.5 $\mathrm{ml} / \mathrm{min}$. Vitronectin containing fractions were pooled and stored at $4^{\circ} \mathrm{C}$ as a slurry in a $70 \%$ saturating concentration of $\left(\mathrm{NH}_{4}\right)_{2} \mathrm{SO}_{4}$. Vitronectin concentration was determined at $280 \mathrm{~nm}$ using $\varepsilon_{280}=1.0 \mathrm{~mL} \cdot \mathrm{mg}^{-1} \cdot \mathrm{cm}^{-1}$ [52] and a molecular weight $=62,000 \mathrm{~g} / \mathrm{mol}$ [53].

To optimize the yield of vitronectin and to follow the purification steps using a quantitative method, the total amount of vitronectin was determined by immunoaffinity chromatography using a mouse anti-human vitronectin monoclonal antibody (1E934) column. Briefly, $2 \mathrm{mg}$ of antibody 1E934 was covalently linked to $1 \mathrm{~mL}$ of NHSactivated Sepharose following the standard protocol and used in HPLC. A standard curve was generated using purified vitronectin stocks, monitoring the area of the peak at several loading concentrations and monitoring at $220 \mathrm{~nm}$. This method gave a linear range from 0 to $19 \mu \mathrm{g}$ of vitronectin. Quantification using the 1E934 antibody indicated that $3 \mathrm{~L}$ of human plasma typically contained $0.2-0.3 \mathrm{mg} / \mathrm{mL}$ vitronectin, which was in good agreement with previous measurements [54-56]. A typical final yield of vitronectin from $3 \mathrm{~L}$ of human plasma using this modified purification method was $\sim 9 \%-10 \%$ (approximately $60-70 \mathrm{mg}$ ).

Cell culture: The human fibrosarcoma cell line (HT1080) was purchased from ATCC and maintained in EMEM supplemented with $10 \%$ FBS and $1 \%$ penicillinstreptomycin solution. The EA.hy 926 cell line, a kind gift from the laboratory of Dr. John Biggerstaff at the University of Tennessee Knoxville, is an immortalized hybridoma cell line created by the fusion between A459 cell (human lung carcinoma) and HUVEC [57]. This cell line expresses factor-VIII related antigen, a feature of highly differentiated vascular endothelium, and the fibrinolytic properties of this cell line are comparable with HUVEC [58]. The EA.hy926 cell line was maintained in DMEM (purchased from GIBCO) containing a high amount of D-glucose (4500 mg/L), $25 \mathrm{mM}$ HEPES, Lglutamine and no sodium-pyruvate. This media was supplemented with $10 \%$ FBS (heat inactivated) and 1\% penicillin-streptomycin solution. Heat inactivation of FBS was achieved by heating the $56^{\circ} \mathrm{C}$ for $30 \mathrm{~min}$. Both of these cell lines were maintained at $37^{\circ} \mathrm{C}$ in a cell- culture incubator containing $5 \% \mathrm{CO}_{2}$.

Measurement of binding to ECM proteins: Protein binding assays were carried out in high-binding, halfarea, flat bottom transparent 96-well plates from Costar. For coating with HSPG, the matrix was dissolved in binding buffer ( $50 \mathrm{mM}$ Tris, $100 \mathrm{mM} \mathrm{NaCl}, 1 \mathrm{mM} \mathrm{CaCl}_{2}$ and $1 \mathrm{mM} \mathrm{MgCl}{ }_{2} \mathrm{pH}$ 7.4) at $5 \mu \mathrm{g} / \mathrm{ml}$ concentration and incubated in wells for $1.5 \mathrm{hr}$ at $37^{\circ} \mathrm{C}$. For coating with collagen-IV, the protein was dissolved in $10 \mathrm{mM}$ acetic acid at $3.6 \mu \mathrm{g} / \mathrm{ml}$ concentration and incubated in the wells at room temperature for $1 \mathrm{hr}$. Coating with GAG 
molecules was carried out at $4^{\circ} \mathrm{C}$ overnight using a concentration of $25 \mu \mathrm{g} / \mathrm{ml}$ for each GAG molecule in $1 \times$ PBS. Following washing to remove unbound components, plates were blocked with a $0.2 \%$ gelatin solution in binding buffer for $1 \mathrm{hr}$ at $37^{\circ} \mathrm{C}$. Monomeric vitronectin or the SMB domain was mixed with PAI-1 (native form or variants) in binding buffer containing $0.1 \%$ Tween-20, and the mixture was incubated at $37^{\circ} \mathrm{C}$ for $1 \mathrm{hr}$. This mixture of these proteins was incubated with the coated plate for $1 \mathrm{hr}$ at $37^{\circ} \mathrm{C}$, followed by washing $(3 \times)$ with $0.1 \%$ Tween-20 containing buffer. Bound vitronectin or SMB domain was probed immunochemically using either a rabbit polyclonal anti-vitronectin antibody or the 1E9 a monoclonal antibody, respectively. Peroxidase conjugated anti-rabbit IgG or anti-mouse $\mathrm{IgG}$, respectively, was used with the ABTS substrate for detection using absorbance at $405 \mathrm{nM}$ in a Synergy Labtek plate reader.

Receptor binding assays: For characterizing the binding of the vitronectin/PAI-1 complex with cell surface receptors, two different approaches were used. Either the receptor was coated on to a 96-well plate, or the receptor was maintained in solution phase during the assay. For the coating of UPAR or integrin, the receptor was incubated with the plate in binding buffer $(50 \mathrm{mM}$ Tris, 100 $\mathrm{mM} \mathrm{NaCl}, 1 \mathrm{mM} \mathrm{CaCl}_{2}$ and $1 \mathrm{mM} \mathrm{MgCl}_{2} \mathrm{pH} 7.4$ ) at 5 $\mu \mathrm{g} / \mathrm{ml}$ concentration for $1 \mathrm{hr}$ at $37^{\circ} \mathrm{C}$. Blocking and detection of the vitronectin/PAI-1 complex were carried out as described above.

For binding assays with receptors in the solution phase, vitronectin and PAI-1 were mixed in binding buffer containing $0.1 \%$ Tween-20, incubated for $1 \mathrm{hr}$ at $37^{\circ} \mathrm{C}$ and then added to plate with or without prior coating with ECM components as described above. After $1 \mathrm{hr}$ incubation and washing to remove unbound proteins, UPAR (20 $\mu \mathrm{g} / \mathrm{ml})$ or integrin $(10 \mu \mathrm{g} / \mathrm{ml})$ in binding buffer containing $0.1 \%$ Tween-20 was incubated with the plate at $37^{\circ} \mathrm{C}$ for $1-1.5 \mathrm{hr}$. For integrin binding, a rabbit polyclonal antibody against the C-terminal domain of the $\alpha \mathrm{v}$-subunit was used, whereas for uPAR binding, a monoclonal antibody against uPAR was used. The buffer for the antibody incubations was PBS containing $0.3 \%$ BSA, 0.5 $\mathrm{mM} \mathrm{CaCl} 2$ and $0.5 \mathrm{mM} \mathrm{MgCl}$, with the metal ions included to ensure that ligand binding to integrins in a metal-dependent fashion was maintained. Peroxidase conjugated anti-mouse or anti-rabbit IgG was used as secondary antibody, with detection using the ABTS substrate as above. For all binding assays the average reading obtained from each treatment condition (normalized with respect to background) was plotted along with the standard error. Statistical significance was determined by two-tailed Student's $t$-tests. $P$-values $<0.05$ were considered significant.

Cell binding assays: For the cell binding assay, the coating of matrix (HSPG or Col-IV), blocking of the coated surface and incubation of the complex of vitronectin and PAI-1 with the coated matrix were carried out as described in the matrix binding assay. High-binding solid-side transparent flat-bottom 96-well plates from Costar were used for this assay. Cells were incubated overnight in the absence or presence of added growth factors, under serum free conditions. VEGF and bFGF were used at $10 \mu \mathrm{g} / \mathrm{ml}$ concentrations, and PMA was used at a $100 \mu \mathrm{g} / \mathrm{ml}$ concentration. Cells were detached from the surface of the culture dish by treatment with $1 \%$ trypsin/EDTA solution, and complete media with serum was used to neutralize the trypsin. Cells were resuspended in serum-free media, and either $100 \mu \mathrm{l}$ of cell suspension containing $10^{5}$ cells $/ \mathrm{ml}$ was added to collagen-coated wells, or $100 \mu \mathrm{l}$ of cell suspension containing $5 \times 10^{5}$ cells $/ \mathrm{ml}$ was added to HSPG coated wells. After incubating at $37^{\circ} \mathrm{C}$ for $1.5 \mathrm{hr}$, unbound cells were removed and bound cells were labeled by adding $100 \mu \mathrm{l}$ serum-free media containing $1 \mu \mathrm{g} / \mathrm{ml}$ calcein at $37^{\circ} \mathrm{C}$ for $30 \mathrm{~min}$ in the incubator. Fluorescent cells bound to the surface were observed under the Axiovert $200 \mathrm{M}$ inverted microscope (Zeiss) using excitation and emission optics suitable for fluorescein. Images were captured using a digital camera (Hamatsu Orca-ER) controlled by Openlab software (Improvision). Images of randomized fields (15 to 18) were taken from each well, and each treatment condition was repeated in triplicate, to determine the average and standard error for number of cells bound per unit field area. Statistical significance was determined by two-tailed Student's $t$-tests. $P$-values < 0.05 were considered significant.

Cell migration assays: Migration experiments were carried out using FluoroBlok cell culture inserts of $8 \mu \mathrm{m}$ pore size from BD Bioscience. These inserts are made of PET membrane containing a dye that blocks transmission of the light in the range of $490-700 \mathrm{~nm}$. If a suitable fluorescent dye is chosen, selective observation of the top or the bottom of the insert can be achieved; thus, use of this insert allows efficient counting of the migrated cells that are bound at the bottom of the insert. Coating of the insert with matrix components was carried out as described above. Vitronectin and PAI-1 were mixed for 1 hr at $37^{\circ} \mathrm{C}$ in binding buffer that contained $0.3 \%$ BSA instead of $0.1 \%$ Tween-20, and the mixtures were subsequently incubated in the inserts for $1 \mathrm{hr}$ at $37^{\circ} \mathrm{C}$. Cells were treated with growth factors and harvested by trypsinization as described above in the cell binding assay section. When Col-IV was used for coating the plate, $150 \mu 1$ of cell suspension containing $10^{6}$ cells $/ \mathrm{ml}$ was added to each insert, and when HSPG was used for coating the plate, $150 \mu \mathrm{l}$ of cell suspension containing $2 \times 10^{5}$ cells $/ \mathrm{ml}$ was added to each insert. $500 \mu \mathrm{l}$ serum-free media was added to the bottom of the each insert, and migration was carried out overnight in the cell culture in- 
cubator. Labeling of the cells was performed by adding $500 \mu \mathrm{l}$ serum-free media containing $1 \mu \mathrm{g} / \mathrm{ml}$ calcein to the bottom of each insert, followed by incubation at $37^{\circ} \mathrm{C}$ for $30 \mathrm{~min}$. Media containing free calcein was replaced by $500 \mu 1$ serum-free media and the labeled cells that had migrated were observed under the microscope (Axiovert $200 \mathrm{M}$ from Zeiss). Photographs of the multiple randomized fields (15 to 18) from the bottom of each insert were taken, and each treatment condition was repeated in triplicate. The average number of cells migrated within the target field area was calculated with standard error. Statistical significance was determined by two-tailed Student's $t$-tests. $P$-values $<0.05$ were considered significant.

Flow cytometry: Cells were incubated overnight in the absence or presence of added growth factors, under serum free conditions. VEGF and bFGF were used at 10 $\mu \mathrm{g} / \mathrm{ml}$ concentrations, and PMA was used at a $100 \mu \mathrm{g} / \mathrm{ml}$ concentration. Cells were detached from the surface of the culture dish by treatment with $1 \%$ trypsin/EDTA solution, and complete media with serum was used to neutralize the trypsin. Cells were resuspended in serum-free media, and $100 \mu \mathrm{l}$ of cell suspension containing at least $10^{6}$ cells for each treatment condition were added to the wells of a 96-well round bottom plate for staining of the cell surface. Cells were incubated with primary antibody against uPAR at 1:40 dilution or antibodies against $\alpha \mathrm{v} \beta 3$, $\alpha \mathrm{v} \beta 5, \alpha 5 \beta 1$ or $\alpha 2 \beta 1$ at a $1: 100$ dilution in FACS buffer (1X PBS containing $1 \%$ BSA and $0.1 \%$ sodium azide, obtained from BD bioscience). The incubation with primary antibody was carried out for $1 \mathrm{hr}$ on ice, washed, and incubated with Alexa-488-conjugated goat antimouse $\operatorname{IgG}(1: 200$ dilution) for $1 \mathrm{hr}$ on ice. Stained cells were washed, fixed by $1 \%$ paraformaldehyde for $20 \mathrm{~min}$ at room temperature, washed again, and transferred into FACS tubes containing $1 \mathrm{ml}$ of FACS buffer. Receptor expression was observed in a FACScan (BD Bioscience) instrument, and the data were analyzed by FlowJo (Tree Star, Inc). All experiments were performed in duplicate.

\section{RESULTS}

Higher-order vitronectin/PAI-1 complexes exhibit increased association with ECM components. Since there are many pathophysiological conditions in which PAI-1 is co-localized with vitronectin in tissues $[10,45,59,60]$, our goal was to test how the presence of these proteins within a complex affects cell adhesion and migration. We began by analyzing binding of higher-order vitronectin/ PAI-1 complexes to the chief components of the ECM, including collagen and proteoglycans. Our experimental design differs from most previous studies, since we assemble vitronectin and PAI-1 into higher-order complexes and then test for binding of these complexes to ECM components, rather than testing each of the single components for binding. Furthermore, instead of using vitronectin solely as a direct binding substrate, we have included other matrix components in our in vitro experiments, e.g. Col-IV and HSPG. Col-IV is an abundant basement membrane component that provides tensile strength $[61,62]$ and interacts with vitronectin [64]. Also, HSPG is an integral basement membrane component found in virtually all mammalian tissues [64,65]. One of the many proposed functions of basement membraneassociated HSPG is to interact with other matrix components, such as laminin, fibronectin, and Col-IV [66,67], and we now test for its interactions with various forms of vitronectin.

A fixed concentration of monomeric vitronectin was mixed with varying concentrations of PAI-1, and the mixture was incubated with plates coated with Col-IV or HSPG. Binding of vitronectin was probed immunochemically. Figures 1(a) and (b) show the dose-dependent increase observed in vitronectin binding to HSPG and Col-IV, respectively, as PAI-1 concentrations are varied. We also observe that the multimeric complex of vitronectin and PAI-1 has a higher propensity to associate with a mixture of both Col-IV and HSPG (data not shown). These findings are consistent with our hypothesis, i.e. that multimeric complexes formed by the interaction of vitronectin with PAI-1 will exhibit enhanced binding to matrix substituents.

HSPG is a proteoglycan that contains heparan sulfate as the glycosaminoglycan constituent. Former work from our laboratory has evaluated binding of native and multimeric vitronectin with another GAG, heparin, demonstrating that multimeric vitronectin exhibits greater binding $[9,68]$. This apparent increased binding of multimeric vitronectin to heparin is attributed to avidity (e.g. multivalent effects) rather than to differences in affinity since the affinity of monomeric vitronectin was measured and shown to be similar to that of a single unit of the multimer [69]. Furthermore, PAI-1 binds to heparin [70]. In order to test whether the observed association of the vitronectin/PAI-1 complex with matrix components (Figure 1) is GAG mediated, we expanded the work with heparin and other GAG molecules. Figure 2 compares monomeric vitronectin and vitronectin/PAI-1 complexes in their ability to interact with various GAG molecules. Monomeric vitronectin binds to all GAG molecules tested, and the vitronectin/PAI-1 complex binds equally well, but does not exhibit increased association. Thus, the increased association of the complex to HSPG appears to be independent of the GAG component.

The interaction between vitronectin and PAI- 1 is primarily mediated through the SMB domain of vitronectin [71], although we recently have found that a more extensive interaction occurs between these two proteins and extends beyond the SMB domain [72]. Because the in- 


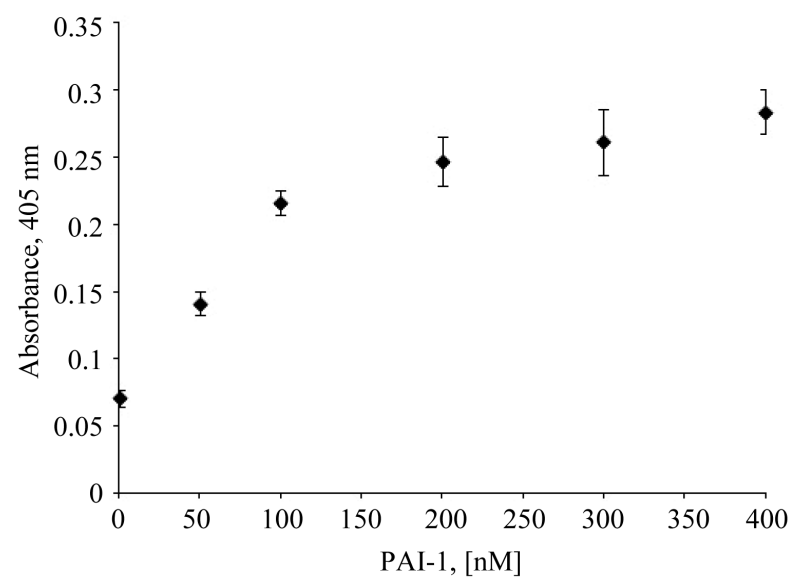

(a)

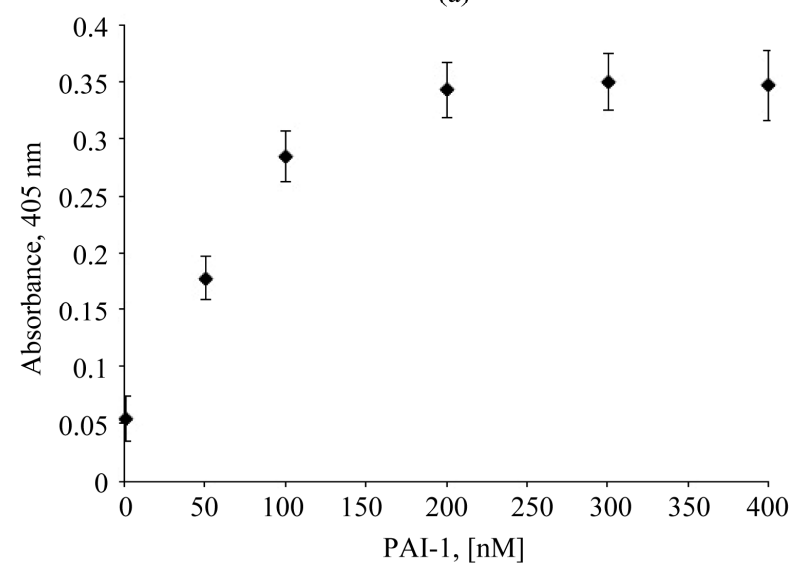

(b)

Figure 1. Association of the vitronectin/PAI-1 complex with HSPG and Col-IV is concentration-dependent. Plates were coated with Col-IV (1 $\mathrm{hr}$ at room temperature) and HSPG (1.5 $\mathrm{hr}$ at $37^{\circ} \mathrm{C}$ ). $100 \mathrm{nM}$ vitronectin was mixed with varying concentrations of PAI- 1 in binding buffer and incubated at $37^{\circ} \mathrm{C}$ for one hour. These preformed mixtures were added to Col-IV(Figure 1(a)) and HSPG- (Figure 1(b)) coated plates following blocking. Binding of vitronectin/PAI-1 complex to the matrix was conducted for $1 \mathrm{hr}$ at $37^{\circ} \mathrm{C}$. Binding of vitronectin to the matrix components was measured immunochemically using a monoclonal antibody (1E9) against vitronectin.

teraction with full-length vitronectin is more complex, we hypothesize that multiple interactions between PAI-1 and full length vitronectin are critical for the assembly of multimeric complexes and thus for increased association with matrix components. In order to test this idea, matrixbinding experiments were conducted with complexes formed by mixing PAI-1 with the isolated SMB domain. Figure 3(a) shows results from SMB/PAI-1 complexes compared to SMB alone binding to HSPG. As predicted, no significant increase in binding of SMB was observed upon mixing with PAI-1; neither was there a decrease in binding due to steric effects of PAI-1. Similar results were observed when Col-IV was used as the solid-phase matrix components (data not shown).

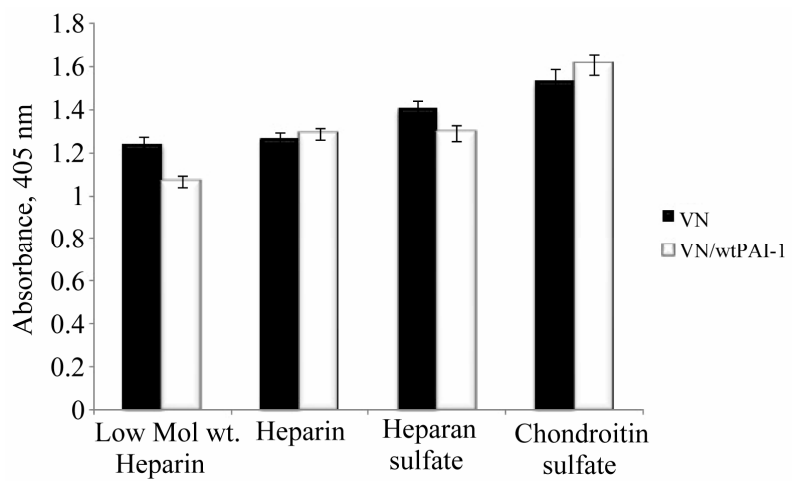

Figure 2. Association of the vitronectin/PAI-1 complex with GAG molecules. Microtiter plates were coated with a variety of GAG molecules at a $25 \mu \mathrm{g} / \mathrm{ml}$ concentration overnight at $4^{\circ} \mathrm{C}$. $50 \mathrm{nM}$ vitronectin was incubated with $100 \mathrm{nM}$ PAI-1, and the mixtures were added to plates coated with GAGs followed by incubation for $1 \mathrm{hr}$ at $37^{\circ} \mathrm{C}$. Binding of vitronectin was quantified immunochemically using a monoclonal antibody (1E9) against vitronectin.

A variant form of PAI-1 containing lysine instead of glutamine at position 123 (Q123K PAI-1) has greatly diminished affinity for vitronectin [73]. Sedimentation velocity experiments on equimolar mixtures of monomeric vitronectin and Q123K-PAI-1 revealed a decreased formation of multimeric complexes (unpublished). In order to test whether this lack of multimerization of vitronectin by Q123K PAI-1 reduces binding to matrix components compared to that observed with native PAI-1, the binding experiments were repeated with mixtures of vitronectin and Q123K PAI-1. Figure 3(b) shows the results of this assay, confirming that the Q123K variant of PAI-1 does not promote increased association of vitronectin with HSPG. Similar results were obtained with Col-IV binding (data not shown).

Ligands that block the interaction of PAI-1 with vitronectin would be expected also to disrupt the enhanced binding to matrix components. Recently we have demonstrated using sedimentation velocity experiments that an octapeptide derived from the RCL of PAI-1 (P14-P7 residues) completely disrupt the interaction between vitronectin and PAI-1 and inhibit the formation of oligomeric complexes (unpublished). We have tested the ability of these peptides to disrupt binding in the matrix association assay. Vitronectin was mixed with PAI-1 in the presence of the octapeptide and the mixture was incubated with HSPG-coated plates. As expected, the octapeptide completely blocked PAI-1 effects on the association of vitronectin with matrix components (Figure 3(b)).

Higher-order vitronectin/PAI-1 complexes exhibit increased association with cell-surface receptors. Vitronectin interacts with numerous cell surface receptors such as uPAR and several integrins, including the "vi- 


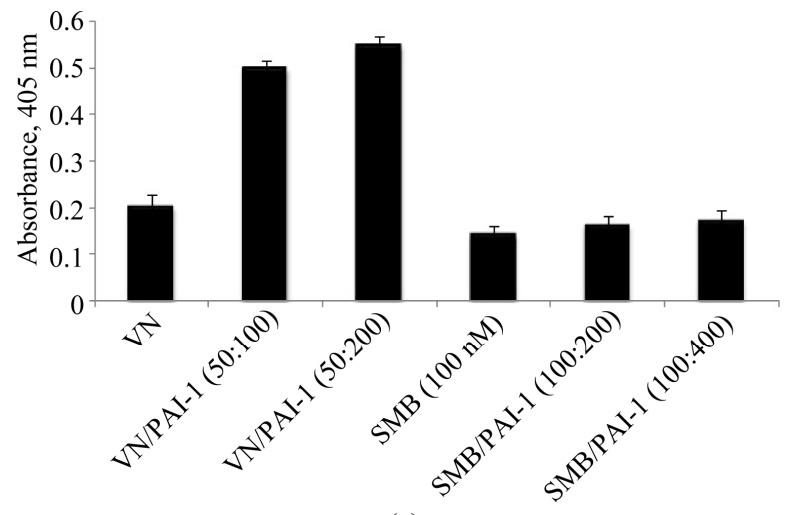

(a)

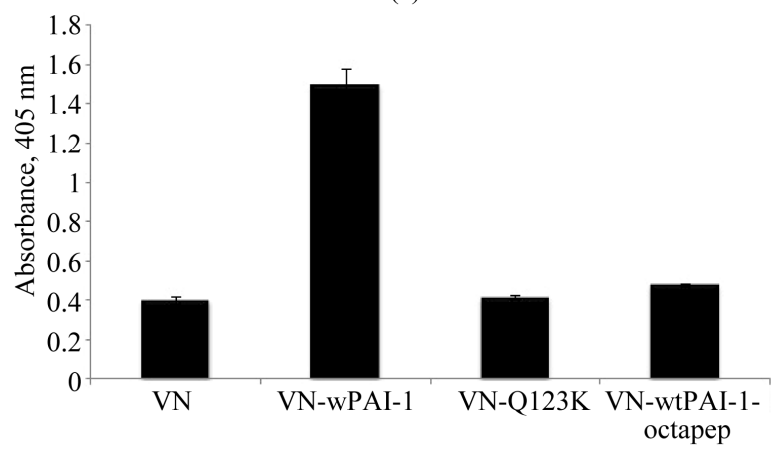

(b)

Figure 3. Requirement for the interaction of PAI-1 with fulllength vitronectin for the formation of oligomeric complex. Figure 3(a) shows that binding of PAI-1 with isolated SMB domain fails to promote increased binding to Col-IV. $50 \mathrm{nM}$ vitronectin and $100 \mathrm{nM}$ SMB were mixed with two different concentrations of PAI-1 corresponding to 1:1 and 1:2 stoichiometry and incubated for $1 \mathrm{hr}$ at $37^{\circ} \mathrm{C}$. The preformed vitronectin/PAI-1 complex and SMB/PAI-1 complexes were added to plates pre-coated with Col-IV. Figure 3(b) shows that mixing of a mutant form of PAI-1 (Q123K, which has very low affinity for vitronectin binding) at $100 \mathrm{nM}$ concentration with vitronectin $(50 \mathrm{nM})$ fails to promote increased binding of vitronectin with Col-IV. Figure 3(b) also shows that interruption of the interaction of vitronectin $(50 \mathrm{nM})$ and PAI-1 (100 nM) with an RCL-mimicking octapeptide (2 $\mathrm{mM})$ blocks the enhanced association of vitronectin with Col-IV otherwise observed. Binding of vitronectin to matrix components for both experiments was measured immunochemically using a monoclonal antibody (1E9) against vitronectin.

tronectin receptor" ( $\alpha \mathrm{v} \beta 3$ and $\alpha \mathrm{v} \beta 5)$. In vitro studies indicate that binding of uPAR to "denatured" multimeric vitronectin is inhibited by the addition of PAI-1 [34,74]. Other studies have shown that binding of $\alpha \mathrm{v} \beta 3$ to multimeric vitronectin is blocked by exogenous PAI-1 [33, 75]. However, we have shown a different behavior for soluble higher-order vitronectin/PAI-1 complexes compared to multimeric vitronectin used as a substratum. The higher-order complexes formed by the interaction between vitronectin and PAI-1 exhibit increased association with $\alpha \mathrm{v} \beta 3$ and GPIIaIIIb compared to monomeric vitronectin [1]. We now extend the previous studies on the vitronectin/PAI-1 complexes to additional integrins and uPAR.

Figure 4(a) shows an increase in vitronectin binding to UPAR in a dose-dependent fashion with varying con-

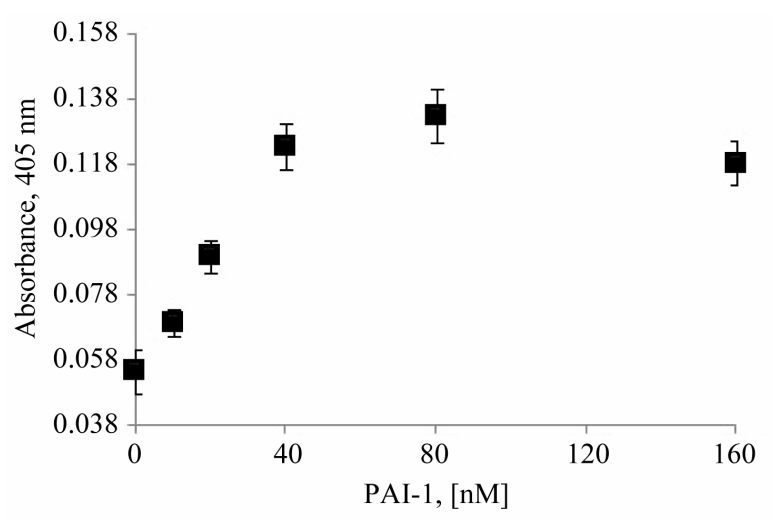

(a)

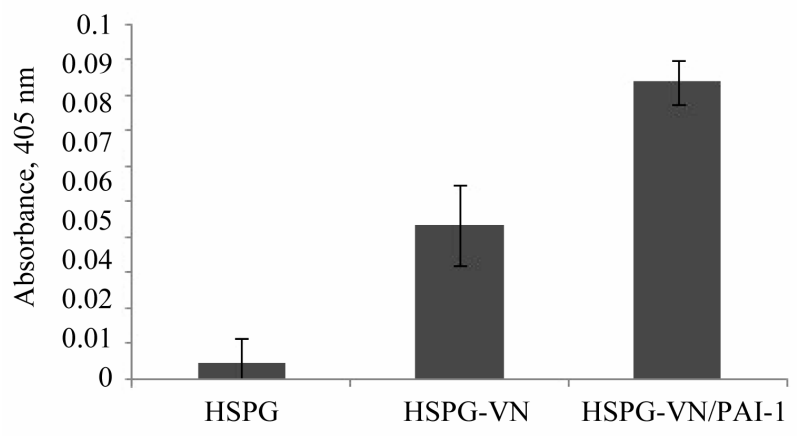

(b)

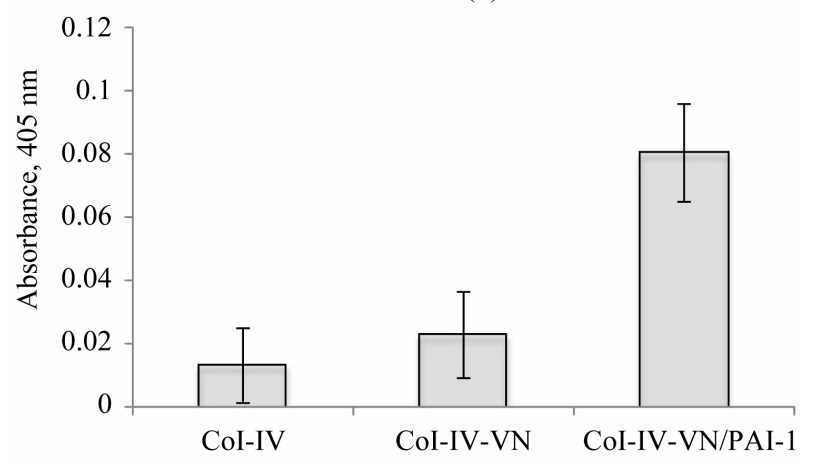

(c)

Figure 4. Increased association of the vitronectin/PAI-1 complex with uPAR. Figure 4(a) shows a dose-dependent increase in vitronectin binding to UPAR with increasing concentrations of PAI-1. $20 \mathrm{nM}$ vitronectin was mixed with varying concentrations of PAI-1 and incubated at $37^{\circ} \mathrm{C}$ for $1 \mathrm{hr}$. Mixtures were added to a uPAR-coated plate, and binding of vitronectin was quantified immunochemically using 1E9. Figures 4(b) and (c) show the binding uPAR to vitronectin/PAI-1 complexes associated with HSPG or Col-IV, respectively. $100 \mathrm{nM}$ vitronectin was mixed with $200 \mathrm{nM}$ PAI-1 and the mixtures were added to HSPG- (Figure 4(b)) or Col-IV- (Figure 4(c)) coated plates. Soluble uPAR was added, and binding of uPAR to the vitronectin/PAI-1 complex was probed immunochemically using an antibody directed against $\mathrm{UPAR}$. 
centrations of PAI-1. In these tests designed to evaluate uPAR binding, we did not observe vitronectin blocking of binding to uPAR by PAI-1. In fact, the higher-order vitronectin/PAI-1 complexes exhibit enhanced binding compared to native monomeric vitronectin. In a different experimental design, we tested for association of soluble UPAR with bound vitronectin/PAI-1 complex that is associated with HSPG or Col-IV (Figures 4(b) and (c), respectively). For these experiments, monomeric vitronectin or the vitronectin/PAI-1 complex was bound to the Col-IV or HSPG substratum, followed by incubation with UPAR. The binding of UPAR was probed by an antibody that recognizes a non-vitronectin-binding epitope on UPAR. While UPAR binding could not be detected to an isolated native vitronectin substratum, a significant increase in binding was observed with the vitronectin/ PAI-1 complex associated with Col-IV or HSPG. A previous study showed that the affinity of uPAR binding to native vitronectin was lower than with "denatured" multimeric vitronectin [76].

The results of binding assays with the vitronectin/ PAI-1 complex and $\alpha \mathrm{v} \beta 3, \alpha \mathrm{v} \beta 5$ and $\alpha 5 \beta 1$ are shown in Figure 5(a). The binding of the complex to $\alpha \mathrm{v} \beta 3$ is enhanced compared to monomeric vitronectin, as previously reported [1], and results with $\alpha \mathrm{v} \beta 5$ and $\alpha 5 \beta 1 \mathrm{mir}-$ ror this behavior. $\alpha 5 \beta 1$ is primarily known as a fibronectin receptor $[77,78]$ that recognizes an RGD sequence in the protein [78]. The $\alpha 5 \beta 1$ integrin shares some functions with $\alpha \mathrm{v} \beta 3$. As observed with $\alpha \mathrm{v} \beta 3$, expression of $\alpha 5 \beta 1$ is minimal in quiescent endothelial cells and increases upon activation of the cells. Also, expression of $\alpha 5 \beta 1$ on endothelial cells can be enhanced by treatment with bFGF or TNF- $\alpha$ [79]. Figure 5(b) shows results that support a specific interaction of vitronectin and $\alpha 5 \beta 1$. In this figure the binding to this integrin by varying concentrations of monomeric vitronectin alone or in complex with equimolar PAI-1 is compared. Monomeric vitronectin shows a concentration-dependent increase in binding to $\alpha 5 \beta 1$. At each concentration, the addition of equimolar PAI-1 to promote formation the higher-order vitronectin/PAI-1 complex leads to increased binding to the integrin $\alpha 5 \beta 1$.

Figure 5(c) shows the corollary results of probing for $\alpha \mathrm{v} \beta 5$ binding to a substratum composed of native vitronectin or the vitronectin/PAI-1 complex using an antibody that recognizes the C-terminal domain of the $\alpha \mathrm{V}$ subunit. Though no detectable binding of $\alpha \mathrm{v} \beta 5$ was observed with monomeric vitronectin, binding was apparent with the vitronectin/PAI-1 complex. As we observed with $\alpha \mathrm{v} \beta 3$ [1], incorporation of PAI-1 in the multimeric complex does not inhibit $\alpha \mathrm{v} \beta 5$ binding to vitronectin and in fact enhances the interaction. However, no binding of $\alpha \mathrm{v} \beta 5$ was detected with this antibody to a substratum with vitronectin or vitronectin/PAI-1 complexes bound to

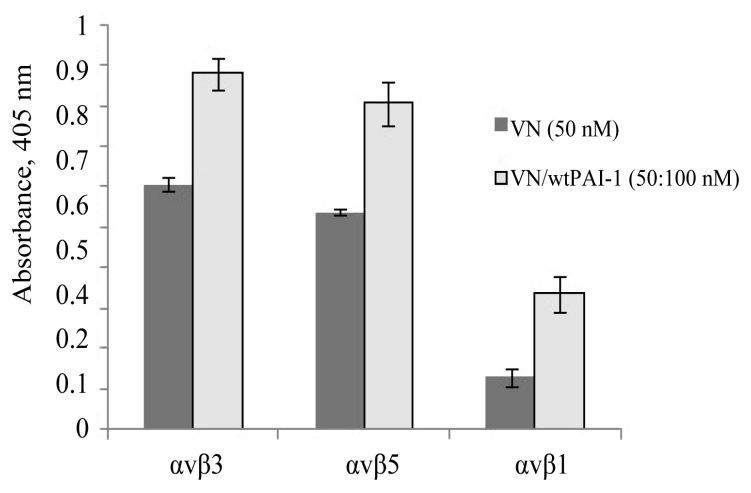

(a)

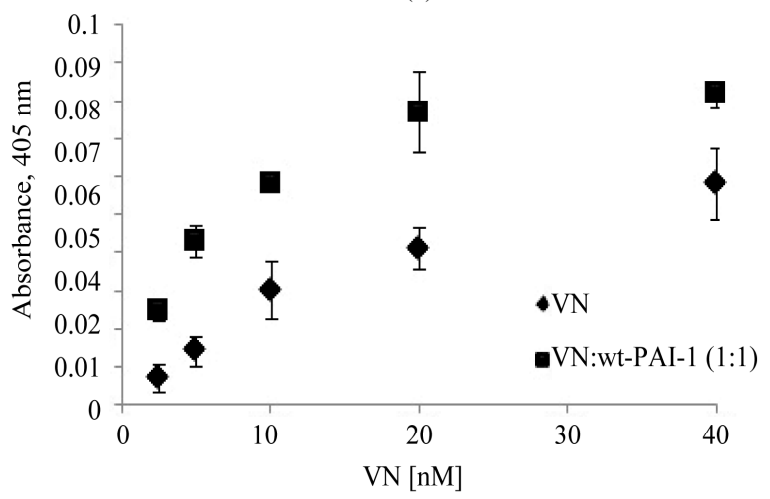

(b)

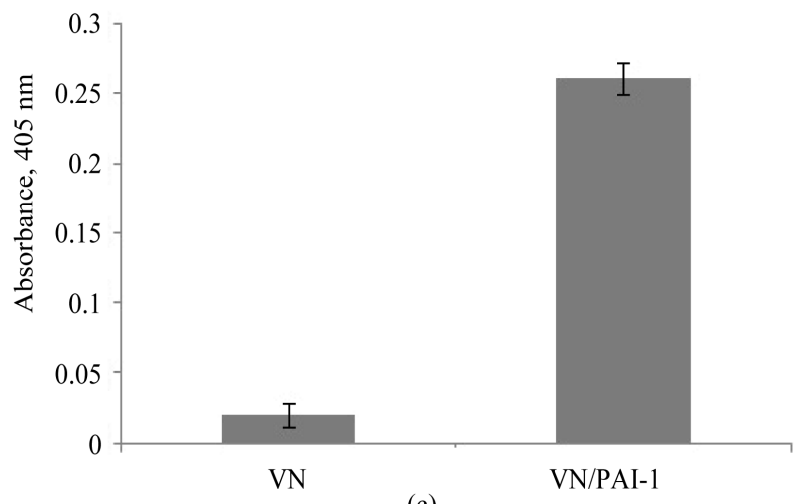

(c)

Figure 5. Increased association of the vitronectin/PAI-1 complex with integrin receptors. Figure 5(a) shows binding of the vitronectin/PAI-1 comlex to different integrin receptors: $\alpha \mathrm{v} \beta 3$, $\alpha \mathrm{v} \beta 5$ and $\alpha 5 \beta 1$. Integrin coating of the plates was performed at $37^{\circ} \mathrm{C}$ for $1 \mathrm{hr}$. $50 \mathrm{nM}$ vitronectin was mixed with $100 \mathrm{nM}$ PAI-1 and incubated for $1 \mathrm{hr}$ at $37^{\circ} \mathrm{C}$. The mixture was added to $\alpha \mathrm{v} \beta 3$-, $\alpha \mathrm{v} \beta 5$ - or $\alpha 5 \beta 1$-coated plates and incubated for $1 \mathrm{hr}$ at $37^{\circ} \mathrm{C} .50$ $\mathrm{nM}$ vitronectin alone or in complex with $100 \mathrm{nM}$ PAI-1 was added to integrin-coated plates. Figure 5(b) shows binding to $\alpha \mathrm{v} \beta 5$ to vitronectin or vitronectin/PAI- 1 complexes. For each sample, the binding of the vitronectin/PAI- 1 complex to $\alpha 5 \beta 1$ is compared to that of vitronectin alone. Figure 5(c) shows binding of $\alpha \mathrm{v} \beta 5$ to vitronectin and the vitronectin/PAI-1 complex. $100 \mathrm{nM}$ vitronectin alone or mixed with $200 \mathrm{nM}$ PAI-1 was used to coat plates. $\alpha \mathrm{v} \beta 5$ was added to the vitronectin- or vitronectin/PAI-1-coated plate and incubated for $2 \mathrm{hr}$ at $37^{\circ} \mathrm{C}$. The binding of the integrin was probed by an antibody against the C-terminus of the $\alpha \mathrm{v}$ subunit. 
other matrix components. Either the mutual binding of vitronectin to the matrix and $\alpha \mathrm{v} \beta 5$ integrin is not possible, or the C-terminal domain of $\alpha \mathrm{v} \beta 5$ is not available for binding to the antibody under these conditions.

Evaluating the impact of the local environment on the ability of the vitronectin/PAI-1 complex to promote cellular adhesion and migration. Previous work has shown that PAI-1 can promote migration of U937 cells (anchorage independent human leukemic cells, showing a high level of expression of UPAR) or melanoma cells (metastatic melanocytes expressing a high level of UPAR and $\alpha v \beta 3$ ) on a vitronectin substratum in a uPAR or vitronectin-dependent manner $[31,32,80]$. On the other hand, PAI-1 has been found to inhibit migration of smooth muscle cells, WISH cells (a transformed human cell line with epitheloid morphology, originally derived from amnion epithelium, capable of migrating under plasmin free conditions) and Hep2 cells (migratory epidermoid carcinoma cells with a high level of uPAR) $[33,81]$. Both WISH and Hep2 cell lines are known to express integrin subunits such as, $\alpha \mathrm{v}, \beta 1, \beta 3$ and $\beta 5$, and they have vitronectin-binding integrin receptors, including $\alpha \mathrm{v} \beta 3, \alpha \mathrm{v} \beta 5, \alpha \mathrm{v} \beta 1$ present on their surface [81]. Thus, the effects of the interaction between PAI-1 and vitronectin on cellular migration/adhesion appear to be influenced by cell type and are likely attributed to variability in cell surface receptors or the specific matrix synthesized by the cells. To compare and/or contrast specific cell responses to this pair of proteins in isolation and in complex, we have chosen two different cell lines for further study. These cell lines, HT1080 (fibrosarcoma cells) and EA.hy926 (endothelial cells), were chosen because they express various receptors that interact with vitronectin and that have been implicated in angiogenesis [34-37]. Formation of new blood vessels is key for tumor development and progression [82,83], and the absence of vitronectin is correlated with decreased angiogenesis in mice [23]. A number of angiogenesis inhibitors designed to disrupt the interaction of $\alpha \mathrm{v} \beta 3$ and $\alpha \mathrm{v} \beta 5$ with vitronectin are currently being evaluated as therapeutics [84-86].

Angiogenesis is initiated by the activation of endothelial cells. Often this activation results from the change in receptor expression on the cell surface mediated by the effect of different growth factors. We used bFGF, VEGF and PMA as modulators of receptor expression in the two cell lines. bFGF has been shown to increase expression of $\alpha \mathrm{v} \beta 3$ in human dermal microvascular endothelial cells [87], and PMA was also found to cause an increase in $\alpha \mathrm{v} \beta 3$ expression in these cells [88]. Brooks et al. reported that bFGF and TNF- $\alpha$ induce angiogenesis by increasing the expression of $\alpha \mathrm{v} \beta 3$ on the vascular endothelium [89]; in this case, angiogenesis could be blocked by a specific antibody against $\alpha \mathrm{v} \beta 3$. Also, Friedlander et $a l$. showed that angiogenesis induced by VEGF and TGF- $\beta$ was blocked by an antibody against $\alpha \mathrm{v} \beta 5$ [90].

Figure 6 illustrates the design of the set of cell-based experiments. Briefly, each cell line was separately treated with the three different stimulants (bFGF, VEGF and PMA) under serum free conditions, with untreated cells in serum free media as a control. Each test group of cells was evaluated in cell binding and migration assays con-

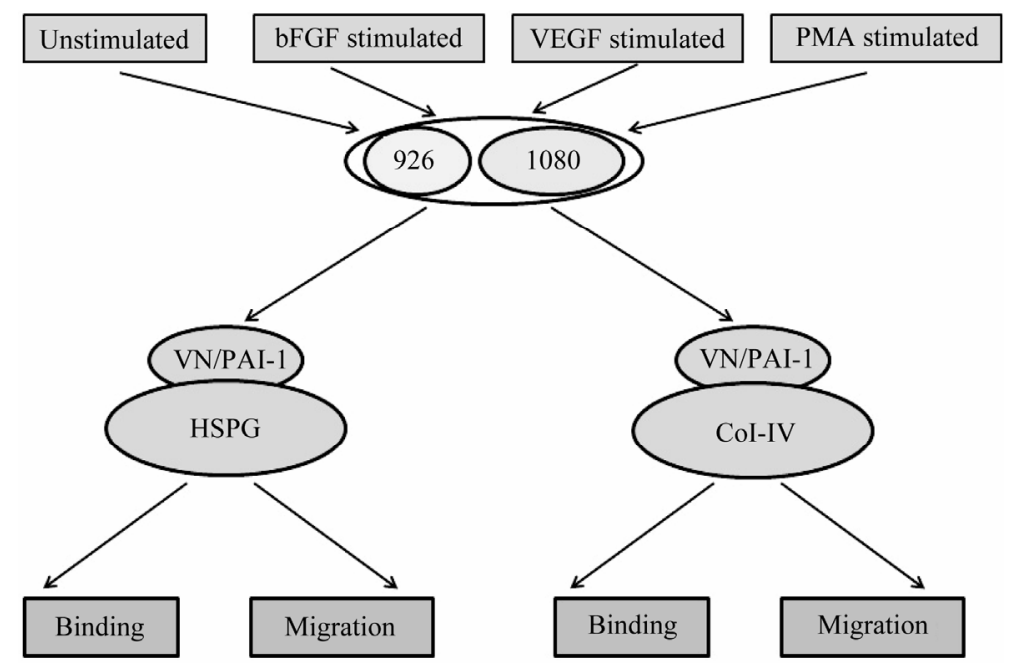

Figure 6. Schematic describing cell binding and migration experiments. 926 cells and HT1080 cells were treated with growth factors and PMA separately. As a control, untreated cells were also used. Various combinations of matrix components were generated by adding vitronectin or the vitronectin/PAI-1 complex to plate coated either with HSPG or Col-IV. Cells exposed to different conditions were evaluated for both binding and migration behavior in the presence of specific matrix components. 
ducted using either Col-IV or HSPG as the substratum. Vitronectin alone or the vitronectin/PAI-1 complex was also bound to the Col-IV or HSPG substratum for separate tests for binding and migration.

Figure 7(a) shows the binding of unstimulated EA.hy926 cells to HSPG alone, or HSPG bound to monomeric vitronectin or the vitronectin/PAI-1 complex. While unstimulated EA.hy926 cells bound to isolated HSPG, the binding increased with vitronectin in the substratum $(\mathrm{P}<$ 0.05); however there was no enhanced binding with the vitronectin/PAI-1 complex attached to the HSPG substratum. Similar results were obtained with 1080 cells prior to stimulation (Figure $\mathbf{7 ( b )}$ ). Thus, in the absence of stimulation, there are no PAI-1-specific effects observed for either cell line. This lack of a PAI-1 effect on cell binding to the HSPG substratum was also true for bFGF-, VEGF- and PMA-stimulated EA.hy926 cells data not shown), where the presence of the vitronectin/ PAI-1 complex neither inhibited nor promoted cellular

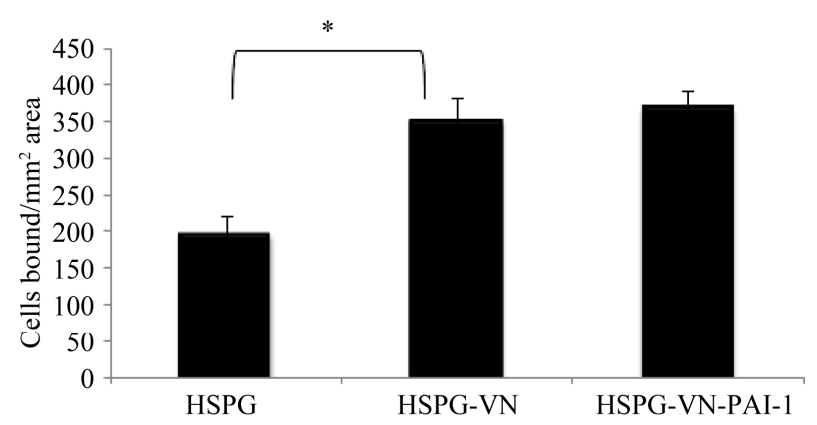

(a)

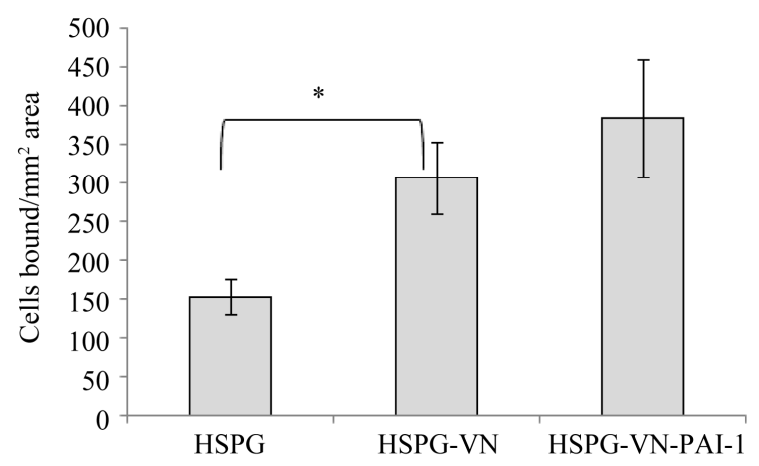

(b)

Figure 7. Binding of unstimulated EA.hy926 and HT1080 cells to the vitronectin/PAI-1 complex associated with HSPG. Figures 7(a) and (b) show the binding of unstimulated EA.hy926 and HT1080 cells to HSPG respectively. $50 \mathrm{nM}$ vitronectin was mixed with $100 \mathrm{nM}$ PAI-1, and the mixtures were added to plates coated with HSPG. Unstimulated cells were added to matrix-coated wells and binding was conducted for $1 \mathrm{hr}$ with HSPG at $37^{\circ} \mathrm{C}$. Bound cells were quantified by labeling after the incubation period with calcein and counting the number of cells bound per $0.13 \mathrm{~mm}^{2}$ area. Statistical significance was determined by two-tailed Student's $t$-tests. $P$-values $<0.05\left(^{*}\right)$ were considered significant. binding compared to vitronectin alone $(P>0.05)$. Binding to the Col-VI substratum for both cell types was not affected by vitronectin or vitronectin/PAI-1 complexes under any of the matrix conditions tested. The binding of the cells under all conditions tested was the same for the Col-IV substratum alone as for the Col-IV substratum with bound vitronectin or vitronectin/PAI-1 complexes, indicating that the binding is dominated by interactions with Col-IV and is insensitive to receptor interactions with vitronectin or modulation by PAI-1.

Tests for cell migration revealed isolated examples where differences were observed that were cell-type specific and dependent on the stimulant and substratum composition. Unstimulated EA.hy926 cells exhibited decreased migration with the vitronectin/PAI-1 complex bound to HSPG compared to the vitronectin-HSPG substratum (data not shown). However, there were no conditions using stimulated cells in which vitronectin- or vitronectin/PAI-1 complex-dependent effects on migration were observed using HSPG as the substratum. The only differences that arose used Col-IV as the substratum, with two representative examples shown in Figure 8. For the case of VEGF-stimulated HT1080 cells (Figure 8(a)), minimal migration is observed on Col-IV alone, while Col-IV bound vitronectin enhances cell migration significantly. Furthermore, the Col-IV substratum with associated vitronectin/PAI-1 complex gives a further enhancement in cell migration. Isolated PAI-1 has no effect in the migration assay. Assays with PMA-stimulated 926 cells migrating on the Col-IV substratum (Figure 8(b)) also show minimal migration on Col-IV alone and an enhancement in cell migration when vitronectin is bound as part of the substratum. However, the higher-order vitronectin/PAI-1 complexes bound to the substratum give contrasting results and, in fact, hamper migration significantly. The only other change among all assay conditions tested was with bFGF-stimulated EA.hy926 on Col-IV supplemented with the vitronectin or vitronectin/ PAI-1 complex. In contrast to PMA-stimulation, the bFGF-treated cells exhibited more migration with the vitronectin/PAI-1 complex added to Col-IV than with vitronectin added to the substratum (data not shown). However, these isolated incidences with differing effects comparing the vitronectin/PAI-1 complex and isolated vitronectin associated with the matrix are more the exception rather than the rule. Indeed, out of the 16 total treatments tested, the only differences comparing vitronectin/PAI-1 complexes with vitronectin alone are observed in these three cases. For both cell lines and all other stimulation conditions, the effects on cell migration of the vitronectin/PAI-1 complex mirror those with monomeric vitronectin associated with either HSPG or Col-IV. Although the effect of vitronectin associated with the matrix components was pro-migratory, the effect of 


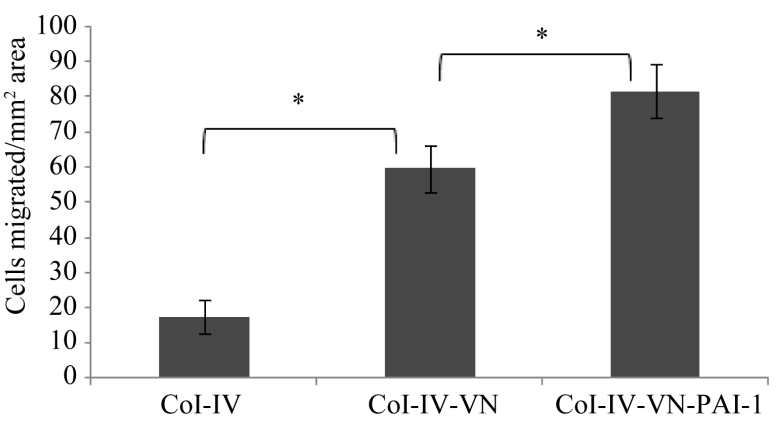

(a)

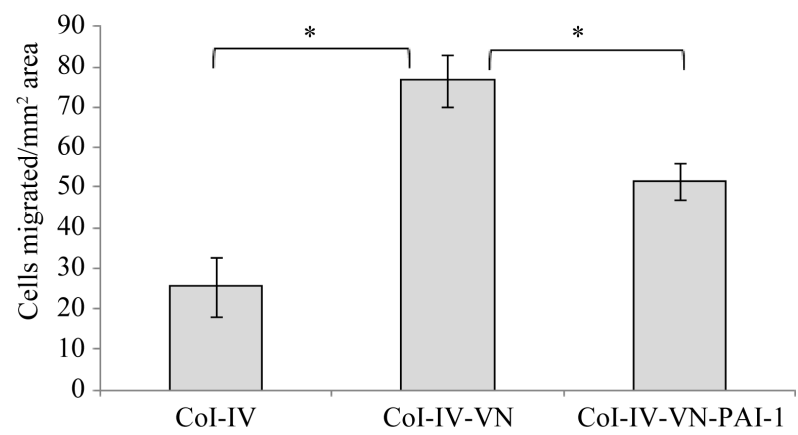

(b)

Figure 8. Migration of VEGF-stimulated 1080 cells and PMAstimulated EA.hy926 cells. A $100 \mathrm{nM}$ concentration of vitronectin was incubated with $200 \mathrm{nM} \mathrm{PAI}-1$ at $37^{\circ} \mathrm{C}$ for $1 \mathrm{hr}$ and the mixtures were added to inserts pre-coated with Col-IV, followed by incubation for $1 \mathrm{hr}$ at $37^{\circ} \mathrm{C}$. VEGF stimulated (Figure 8(a)) 1080 cells and PMA (Figure 8(b)) stimulated 926 cells were added to inserts and migration was continued overnight at $37^{\circ} \mathrm{C}$. Cells were labeled after the overnight experiment with calcein, and the number of cells migrated per $0.13 \mathrm{~mm}^{2}$ area is plotted. Statistical significance was determined by twotailed Student's $t$-tests. $P$-values $<0.05\left(^{*}\right)$ were considered significant.

the higher-order complex was variable and subject to the specific cellular microenvironment.

Evaluation of receptor expression by FACS analysis shows variable expression upon stimulation. A range of matrix components and cell surface receptors, including uPAR and integrins, mediates binding of cells to the substratum. Having tested the effect of the vitronectin/PAI-1 complex under an assortment of conditions with variable results made it important to examine the receptor expression profile of the HT1080 and EA.hy926 cells under the conditions tested. Flow cytometry was used to check for a subset of the $\sim 24$ different integrin heterodimers [2]) that can be expressed on human cells. This includes those primarily involved in vitronectin recognition $(\alpha \mathrm{v} \beta 3$ and $\alpha v \beta 5$ ) that can be induced in some cell types by bFGF and VEGF. Since we observed Col-IV to mediate binding regardless of vitronectin or the vitronectin/PAI-1 complex, and since the only cell migration differences were observed on Col-IV, it was important to test for collagen receptors. Among the four characterized collagen recap- tors $(\alpha 1 \beta 1, \alpha 2 \beta 1, \alpha 10 \beta 1$ and $\alpha 11 \beta 1)$ [26], we focused on $\alpha 2 \beta 1$, which is found on endothelial cells and recognizes different kinds of collagens including Col-IV [91,92]. We also checked the expression of $\alpha 5 \beta 1$ because we found that vitronectin interacts with this receptor, and we observed that this interaction was even more prominent with the vitronectin/PAI-1 complex. Moreover, it has been observed that bFGF induces increased expression of $\alpha 5 \beta 1$ on endothelial cells [79]. Finally, many studies indicate the importance of UPAR in regulating PAI-1 effects on cellular adhesion and migration via vitronectin [31,74], so uPAR expression was also checked.

Figures 9(a) and (b) show the basal expression of all the five receptors in unstimulated EA.hy926 and HT1080 cells, respectively. All of the tested receptors were expressed in both cell lines. Expression of $\alpha 2 \beta 1$ was the highest in the HT1080 cells, followed by lower levels of expression of $\alpha 5 \beta 1, \alpha \mathrm{v} \beta 5$, and $\alpha \mathrm{v} \beta 3$. Levels of uPAR were also low in the HT1080 cells. For the EA.hy926 cells, $\alpha 5 \beta 1$ expression was the highest under basal conditions, followed by decreasing levels of expression by $\alpha 2 \beta 1, \alpha \mathrm{v} \beta 3, \alpha \mathrm{v} \beta 5$ and uPAR. The expression profile of each of these receptors was also evaluated upon treatment with the three growth factors. Expression of uPAR, $\alpha \mathrm{v} \beta 3$ and $\alpha 2 \beta 1$ appeared unchanged in both cell lines upon growth factor treatment (data not shown). Small changes in the expression of $\alpha \mathrm{v} \beta 5$ are observed in both cell lines upon application of bFGF and VEGF (Figures 9(c) and (d)). Also, while PMA treatment caused a greater increase in expression of $\alpha \mathrm{v} \beta 5$ on HT1080 cells (Figure 9(d)) relative to bFGF and VEGF treatment, this increase was not observed with EA.hy926 cells (Figure 9(c)). Furthermore, while bFGF and VEGF treatment did not affect the expression of $\alpha 5 \beta 1$, application of PMA caused a moderate decrease in the expression of $\alpha 5 \beta 1$ on EA.hy926 cells (Figure 9(e)) and a slight increase in expression on HT1080 cells (Figure 9(f)). In summary, although some changes were noted upon stimulating the cells, such changes appeared modest overall and was not correlated with the few differences observed in cell migration behavior for vitronectin vs vitronectin/PAI-1 complexes.

\section{DISCUSSION}

A role for PAI-1 in localizing and regulating vitronectin function in the ECM. The goal of these studies was to build a representative picture of vitronectin-dependent cell adhesion and migration and how it is influenced by incorporation of PAI-1 into higher-order complexes with vitronectin and association with ECM components. These studies have used multimers promoted by PAI-1 binding that more likely replicate a physiological scenario that other forms of multimeric vitronectin generated by denaturation and renaturation have failed to 


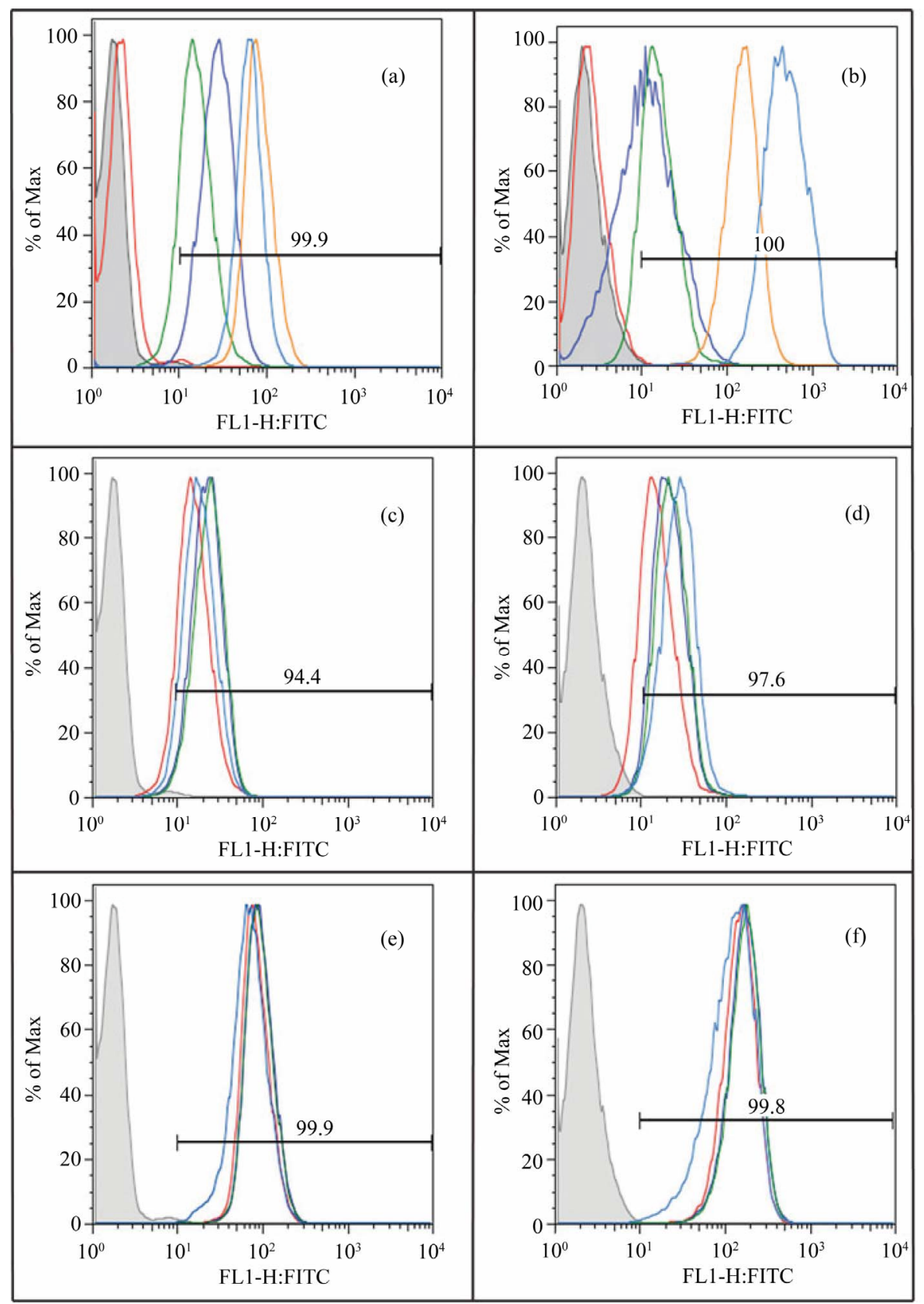

Figure 9. Evaluation of cell surface receptor expression by flow cytometry. Figures 9(a) and (b) compare the basal expression level of uPAR (red), $\alpha \mathrm{v} \beta 3$ (blue), $\alpha \mathrm{v} \beta 5$ (green), $\alpha 5 \beta 1$ (brown) and $\alpha 2 \beta 1$ (turquoise) on unstimulated EA.hy 926 cells and unstimulated 1080 cells respectively. Figures 9(c) and (d) compare the expression of $\alpha \mathrm{v} \beta 5$ on EA.hy926 and HT1080 cells respectively, under the influence of different growth factors-unstimulated (red), bFGF (blue), VEGF (green) and PMA (turquoise). Figures 9(e) and (f) compare the expression of $\alpha 5 \beta 1$ on EA.hy926 and HT1080 cells respectively, under the influence of different growth factors-unstimulated (red), bFGF (blue), VEGF (green) and PMA (turquoise). The histogram shown in gray indicates unstained cells. The horizontal line indicates the average percentage of the population showing signal over background.

achieve. Our previous work on formation of the higherorder complexes demonstrated that mixing vitronectin with various concentrations of PAI-1 yielded long-lived multimeric complexes that assembled in a concentration- dependent manner [47]. Assuming that these complexes mimic those found in tissues, we reasoned that the extent of association with ECM components should be proportional to the amount of the multimeric complexes pro- 
duced. Consistently, increasing concentrations of PAI-1 gave dose-dependent increases in the amount of vitronectin associated with either HSPG or Col-IV and support their relevance for the localization and function of vitronectin in tissues. Furthermore, another observation underscoring the distinctive properties of these vitronectin/PAI-1 multimeric complexes is that they do not show enhanced binding with different GAGs including heparin, a property of denatured multimeric vitronectin [9].

The specificity of the assembly process and resulting matrix component binding was demonstrated with PAI-1 variants that bind weakly to vitronectin and with peptides that block the interaction between the two proteins. Furthermore, the successful assembly of the multimeric complexes requires the binding of PAI-1 to full-length vitronectin. Restricting the interactions to the isolated SMB domain prohibits higher-order complex formation and association with the matrix components. Clearly it is the interaction between vitronectin and PAI-1 that leads to the transformation into the higher-order multimeric complexes required for increased association with the matrix components.

The generally accepted role for PAI-1 is as an inhibitor that disrupts the interactions of vitronectin with receptors such as uPAR or integrins. According to previous studies, the interaction between UPAR and vitronectin was inhibited by exogenously added PAI-1 [31,74]. The uPARbinding site on the SMB domain overlaps with the PAI1-binding site, so that PAI-1 and uPAR compete for binding to vitronectin [93]. Similar results were observed with vitronectin binding to $\alpha \mathrm{v} \beta 3$; binding of vitronectin to $\alpha \mathrm{v} \beta 3$ was blocked by the addition of PAI-1 $[33,75]$. Though the RGD domain responsible for integrin recognition does not appear to be directly blocked by PAI-1 from analysis of the crystal structure obtained on the SMB domain and PAI-1 [71], steric interference between these sites has been attributed to the observed inhibition of PAI-1 on the vitronectin-integrin interaction and as a proposed molecular switch $[33,74,94]$. Our approach has been different, assembling complexes of vitronectin and PAI-1 and testing for binding to receptors. With varying concentrations of PAI-1, binding of vitronectin to UPAR increased in a dose-dependent fashion. Thus, the presence of PAI-1 within higher-order complexes does not preclude the binding of vitronectin to uPAR. In a complementary approach, we directly probed the binding of UPAR to the vitronectin/PAI-1 complexes in isolation or bound to other matrix components. For directly probing uPAR binding, an antibody was chosen that recognized an epitope that does not interfere with the interaction between UPAR and vitronectin. This approach supported the observation that UPAR binding was not blocked by the presence of PAI-1. Since the binding sites for UPAR and PAI-1 on vitronectin at least partially overlap, this result indicates that features of the higher-order complexes can accommodate binding via sites that are localized to other regions on the molecule.

We have also tested the ability of these multimeric complexes to recognize different integrin receptors. Our former work established that these complexes associate more readily with $\alpha \mathrm{v} \beta 3$ and $\alpha \operatorname{IIb} \beta 3$ integrins compared to monomeric vitronectin alone [1]. In the current study, we expanded this observation to show that PAI-1 present in the multimeric complexes also did not block vitronectin binding to integrins $\alpha v \beta 5$ and $\alpha 5 \beta 1$. Though the interaction with $\alpha 5 \beta 1$ was weaker compared to $\alpha \mathrm{v} \beta 3$ and $\alpha \mathrm{v} \beta 5$, the multimeric complexes showed an increased association with $\alpha 5 \beta 1$ compared to monomeric vitronectin. To confirm this result, we probed $\alpha \mathrm{v} \beta 5$ binding to vitronectin and or vitronectin/PAI-1 complexes and observed similar increases in binding to the complexes. Curiously, binding of $\alpha \mathrm{v} \beta 5$ to either monomeric or multimeric vitronectin could not be detected when these proteins were bound to the ECM components. It appears that the antibody probe has low affinity for the integrin when it is bound to vitronectin or the complex associated with the matrix components like Col-IV and HSPG.

The role of PAI-1 in complex with vitronectin on cell adhesion and migration varies with cell type and environment. The effect of PAI-1 on the regulation of cellular adhesion and migration on vitronectin is hotly debated. There is no consensus regarding the influence of these two proteins on the regulation of cell-matrix interactions. Although most studies indicate that PAI-1 inhibits cell adhesion to vitronectin, published work contains opposing claims regarding migration. Some studies indicate that PAI-1 inhibits cell binding and in effect promotes migration, while others suggest that PAI-1 inhibits vitronectin-dependent migration $[31,33,74,81]$. The majority of these studies addressed the role of exogenously added PAI-1 in regulating cellular adhesion and migration mediated by multimeric vitronectin as a substratum. Instead, our approach tests PAI-1 in complex with vitronectin, as it will be found in vivo. Furthermore, we utilize higher-order complexes of vitronectin and PAI-1 that more closely mimic the forms found in the ECM. Also, we have tested a limited number of ways in which the pericellular microenvironments may be modulated; the tests on ECM components and stimulation that induces different patterns of cell-surface expression of receptors on two cell types focuses on a small subset of the variability that will be found in nature.

The results of our adhesion studies with pre-formed vitronectin/PAI-1 complexes differ from findings when PAI-1 is added exogenously to a vitronectin substratum. The complexes with PAI-1 neither inhibited nor promoted cellular attachment relative to vitronectin alone, in 
spite of the fact that there appeared to be an increase of vitronectin association to isolated matrix components when complexed with PAI-1. This result was similar with both cell lines, regardless of stimulation with growth factors. The results with cell migration show that vitronectin promotes migration under all conditions, as expected. However the effect of PAI-1 in complexes with vitronectin was variable. Under most conditions, PAI-1 gave no difference in migration relative to vitronectin alone, although a small subset of experiments showed either pro-migratory or anti-migratory effects. These results varied by cell type, matrix substratum and stimulatory conditions, without a predictable pattern for the effects. The effect of isolated PAI-1 bound to the matrix components was also tested, but no effect on migration was observed.

Results from other studies are also variable. For example, vitronectin was found to promote migration of smooth muscle cells and keratinocytes [95,96]. Also, some studies have shown that PAI-1 does not affect cellular attachment, but causes a decrease in cellular migration [33]. Stefansson et al. suggested that the lack of an effect of PAI-1 on cellular attachment was due to the presence of receptors that recognized matrix components other than vitronectin [33]. Following similar reasoning, we used flow cytometry study to characterize expression of a number of receptors (uPAR, $\alpha \mathrm{v} \beta 3, \alpha \mathrm{v} \beta 5, \alpha 5 \beta 1, \alpha 2 \beta 1$ ) in the two cell lines upon stimulation with growth factors. Under all conditions, the collagen receptor $\alpha 2 \beta 1$ exhibited high expression in both the cell lines. This is consistent with our observation that cell binding on the Col-IV substratum was not influenced by vitronectin alone or in complex with PAI-1. Also, uPAR was not expressed at significant levels under any of the conditions tested. Since uPAR preferentially binds vitronectin over HSPG or Col-IV, the absence of this receptor may account for the relative insensitivity of the cells to the presence of monomeric or multimeric vitronectin in the matrix.

Though some increase in cell binding could be observed with monomeric vitronectin attached to the HSPG substratum, the higher-order complexes did not facilitate additional cell binding. The results from our direct matrix-binding assay established that these vitronectin/ PAI-1 complexes exhibit increased binding to HSPG, leading us to anticipate a concomitant increase in cell binding under these conditions. Since no effect on binding to the preformed vitronectin/PAI-1 complexes was observed, it appears that the situation is more complicated than simple protein abundance leading to individual binding sites in the substratum. This is perhaps not surprising, since cells maintain multiple points of contact with the substratum that are not uniform. For example, integrin clustering at focal adhesions at the leading edge of cells is a phenomenon thought to add to the strength of cell binding at these locations [97]. A multimeric higherorder form of vitronectin could, in turn, provide multiple contacts for integrins clustered in such foci and could result in a greater avidity for binding without increasing total cell numbers bound to the matrix. Alternatively, there may be a steric effect where the binding of one cell masks multivalent complexes so that they are inaccessible to other cells. Regardless, the association of PAI-1 with vitronectin did not inhibit cellular attachment relative to isolated monomeric vitronectin in the substratum, which contrasts with results using exogenous PAI-1.

The variable results with cell migration under these conditions reveal a complicated scenario that depends on the micro-milieu at the cell-matrix interface. As expected, the increase observed in cell migration with vitronectin in the substratum was uniformly enhanced relative to isolated HSPG or Col-IV. In contrast, the effects on migration due to PAI-1 in the multimeric complex with vitronectin were significant only in few cases, and they were not dramatic compared to the stimulation observed with vitronectin alone. Consistently, none of the growth factors gave an appreciable change in the expression of the receptors tested. All changes observed were moderate. Thus, PAI-1 bound to the substratum via its binding partner vitronectin will not necessarily promote or inhibit migration and will be primarily influenced by the pericellular environment.

\section{REFERENCES}

[1] Minor, K.H. and Peterson, C.B. (2002) Plasminogen activator inhibitor type 1 promotes the self-association of vitronectin into complexes exhibiting altered incorporation into the extracellular matrix. Journal of Biological Chemistry, 277, 10337-10345. doi:10.1074/jbc.M109564200

[2] Schvartz, I., Seger, D. and Shaltiel, S. (1999) Vitronectin. International Journal of Biochemistry \& Cell Biology, 31, 539-544. doi:10.1016/S1357-2725(99)00005-9

[3] Seiffert, D. (1997) Constitutive and regulated expression of vitronectin. Histology and Histopathology, 12, 787797.

[4] Volker, W., Hess, S., Vischer, P. and Preissner, K.T. (1993) Binding and processing of multimeric vitronectin by vascular endothelial cells. Journal of Histochemistry \& Cytochemistry, 41, 1823-1832. doi:10.1177/41.12.7504009

[5] Tomasini, B.R. and Mosher, D.F. (1988) Conformational states of vitronectin: Preferential expression of an antigenic epitope when vitronectin is covalently and noncovalently complexed with thrombin-antithrombin III or treated with urea. Blood, 72, 903-912.

[6] De Boer, H.C., de Groot, P.G., Bouma, B.N. and Preissner, K.T. (1993) Ternary vitronectin-thrombin-antithrombin III complexes in human plasma. Detection and 
mode of association. Journal of Biological Chemistry, 268, 1279-1283.

[7] Barnes, D.W., Reing, J.E. and Amos, B. (1985) Heparin-binding properties of human serum spreading factor. Journal of Biological Chemistry, 260, 9117-9122.

[8] Lane, D.A., Flynn, A.M., Pejler, G., Lindahl, U., Choay, J. and Preissner, K. (1987) Structural requirements for the neutralization of heparin-like saccharides by complement $\mathrm{S}$ protein/vitronectin. Journal of Biological Chemistry, 262, 16343-16348.

[9] Hayashi, M., Akama, T., Kono, I. and Kashiwagi, H. (1985) Activation of vitronectin (serum spreading factor) binding of heparin by denaturing agents. Journal of Biochemistry, 98, 1135-1138.

[10] Owensby, D.A., Morton, P.A., Wun, T.C. and Schwartz, A.L. (1991) Binding of plasminogen activator inhibitor type-1 to extracellular matrix of Hep G2 cells. Evidence that the binding protein is vitronectin. Journal of Biological Chemistry, 266, 4334-4340.

[11] Lawrence, D.A., Palaniappan, S., Stefansson, S., Olson, S.T., Francis-Chmura, A.M., Shore, J.D. and Ginsburg, D. (1997) Characterization of the binding of different conformational forms of plasminogen activator inhibitor-1 to vitronectin. Implications for the regulation of pericellular proteolysis. Journal of Biological Chemistry, 272, 76767680. doi:10.1074/jbc.272.12.7676

[12] Arroyo De Prada, N., Schroeck, F., Sinner, E.K., Muehlenweg, B., Twellmeyer, J., Sperl, S., Wilhelm, O.G., Schmitt, M. and Magdolen, V. (2002) Interaction of plasminogen activator inhibitor type-1 (PAI-1) with vitronectin. European Journal of Biochemistry, 269, 184192. doi:10.1046/j.0014-2956.2002.02639.x

[13] Tschopp, J., Masson, D., Schafer, S., Peitsch, M. and Preissner, K.T. (1988) The heparin binding domain of S-protein/vitronectin binds to complement components C7, C8, and C9 and perforin from cytolytic T-cells and inhibits their lytic activities. Biochemistry, 27, 41034109. doi:10.1021/bi00411a029

[14] Kanse, S.M., Kost, C., Wilhelm, O.G., Andreasen, P.A. and Preissner, K.T. (1996) The urokinase receptor is a major vitronectin-binding protein on endothelial cells. Experimental Cell Research, 224, 344-353. doi:10.1006/excr.1996.0144

[15] Huang, X., Wu, J., Spong, S. and Sheppard, D. (1998) The integrin alphavbeta 6 is critical for keratinocyte migration on both its known ligand, fibronectin, and on vitronectin. Journal of Cell Science, 111, 2189-2195.

[16] Dahm, L.M. and Bowers, C.W. (1998) Vitronectin regulates smooth muscle contractility via alphav and betal integrin. Journal of Cell Science, 111, 1175-1183.

[17] Memmo, L.M. and McKeown-Longo, P. (1998) The alphavbeta5 integrin functions as an endocytic receptor for vitronectin. Journal of Cell Science, 111, 425-433.

[18] Schnapp, L.M., Hatch, N., Ramos, D.M., Klimanskaya, I.V., Sheppard, D. and Pytela, R. (1995) The human integrin alpha 8 beta 1 functions as a receptor for tenascin, fibronectin, and vitronectin. Journal of Biological Chemistry, 270, 23196-23202. doi:10.1074/jbc.270.39.23196
[19] Nishimura, S.L., Sheppard, D. and Pytela, R. (1994) Integrin alpha $\mathrm{v}$ beta 8 . Interaction with vitronectin and functional divergence of the beta 8 cytoplasmic domain. Journal of Biological Chemistry, 269, 28708-28715.

[20] Boettiger, D., Lynch, L., Blystone, S. and Huber, F. (2001) Distinct ligand-binding modes for integrin alpha(v)beta(3)-mediated adhesion to fibronectin versus vitronectin. Journal of Biological Chemistry, 276, 3168431690. doi:10.1074/jbc.M103997200

[21] Podor, T.J., Campbell, S., Chindemi, P., Foulon, D.M., Farrell, D.H., Walton, P.D., Weitz, J.I. and Peterson, C.B. (2002) Incorporation of vitronectin into fibrin clots. Evidence for a binding interaction between vitronectin and gamma A/gamma' fibrinogen. Journal of Biological Chemistry, 277, 7520-7528. doi:10.1074/jbc.M109677200

[22] Eitzman, D.T., Westrick, R.J., Nabel, E.G. and Ginsburg, D. (2000) Plasminogen activator inhibitor-1 and vitronectin promote vascular thrombosis in mice. Blood, 95, 577-580.

[23] Jang, Y.C., Tsou, R., Gibran, N.S. and Isik, F.F. (2000) Vitronectin deficiency is associated with increased wound fibrinolysis and decreased microvascular angiogenesis in mice. Surgery, 127, 696-704. doi: $10.1067 / \mathrm{msy} .2000 .105858$

[24] Kanse, S.M., Matz, R.L., Preissner, K.T. and Peter, K. (2004) Promotion of leukocyte adhesion by a novel interaction between vitronectin and the beta2 integrin Mac-1 (alphaMbeta2, CD11b/CD18). Arteriosclerosis, Thrombosis, and Vascular Biology, 24, 2251-2256. doi:10.1161/01.ATV.0000146529.68729.8b

[25] Hess, S., Kanse, S.M., Kost, C. and Preissner, K.T. (1995) The versatility of adhesion receptor ligands in haemostasis: Morpho-regulatory functions of vitronectin. Thrombosis and Haemostasis, 74, 258-265.

[26] Barczyk, M., Carracedo, S. and Gullberg, D. (2010) Integrins. Cell and Tissue Research, 339, 269-280. doi:10.1007/s00441-009-0834-6

[27] Felding-Habermann, B. and Cheresh, D.A. (1993) Vitronectin and its receptors. Current Opinion in Cell Biology, 5, 864-868. doi:10.1016/0955-0674(93)90036-P

[28] Lawrence, D., Strandberg, L., Grundstrom, T. and Ny, T. (1989) Purification of active human plasminogen activator inhibitor 1 from Escherichia coli. Comparison with natural and recombinant forms purified from eucaryotic cells. European Journal of Biochemistry, 186, 523-533. doi:10.1111/j.1432-1033.1989.tb15238.x

[29] Estreicher, A., Muhlhauser, J., Carpentier, J.L., Orci, L. and Vassalli, J.D. (1990) The receptor for urokinase type plasminogen activator polarizes expression of the protease to the leading edge of migrating monocytes and promotes degradation of enzyme inhibitor complexes. Journal of Cell Biology, 111, 783-792. doi:10.1083/jcb.111.2.783

[30] Vassalli, J.D., Sappino, A.P. and Belin, D. (1991) The plasminogen activator/plasmin system. Journal of Clinical Investigation, 88, 1067-1072. doi:10.1172/JCI115405

[31] Waltz, D.A., Natkin, L.R., Fujita, R.M., Wei, Y. and Chapman, H.A. (1997) Plasmin and plasminogen activa- 
tor inhibitor type 1 promote cellular motility by regulating the interaction between the urokinase receptor and vitronectin. Journal of Clinical Investigation, 100, 58-67. doi:10.1172/JCI119521

[32] Stahl, A. and Mueller, B.M. (1997) Melanoma cell migration on vitronectin: Regulation by components of the plasminogen activation system. International Journal of Cancer, 71, 116-122.

doi:10.1002/(SICI)1097-0215(19970328)71:1<116::AIDIJC19>3.0.CO;2-G

[33] Stefansson, S. and Lawrence, D.A. (1996) The serpin PAI-1 inhibits cell migration by blocking integrin alpha $\mathrm{V}$ beta 3 binding to vitronectin. Nature, 383, 441-443. doi:10.1038/383441a0

[34] Bajou, K., Noel, A., Gerard, R.D., Masson, V., Brunner, N., Holst-Hansen, C., Skobe, M., Fusenig, N.E., Carmeliet, P., Collen, D. and Foidart, J.M. (1998) Absence of host plasminogen activator inhibitor 1 prevents cancer invasion and vascularization. Nature Medicine, 4, 923928. doi:10.1038/nm0898-923

[35] Gutierrez, L.S., Schulman, A., Brito-Robinson, T., Noria, F., Ploplis, V.A. and Castellino, F.J. (2000) Tumor development is retarded in mice lacking the gene for urokinase-type plasminogen activator or its inhibitor, plasminogen activator inhibitor-1. Cancer Research, 60, 5839-5847.

[36] Stefansson, S., Petitclerc, E., Wong, M.K., McMahon, G.A., Brooks, P.C. and Lawrence, D.A. (2001) Inhibition of angiogenesis in vivo by plasminogen activator inhibitor-1. Journal of Biological Chemistry, 276, 8135-8141. doi:10.1074/jbc.M007609200

[37] McMahon, G.A., Petitclerc, E., Stefansson, S., Smith, E., Wong, M.K., Westrick, R.J., Ginsburg, D., Brooks, P.C. and Lawrence, D.A. (2001) Plasminogen activator inhibitor-1 regulates tumor growth and angiogenesis. Journal of Biological Chemistry, 276, 33964-33968. doi:10.1074/jbc.M105980200

[38] Devy, L., Blacher, S., Grignet-Debrus, C., Bajou, K., Masson, V., Gerard, R.D., Gils, A., Carmeliet, G., Carmeliet, P., Declerck, P.J., Noel, A., and Foidart, J.M. (2002) The pro- or antiangiogenic effect of plasminogen activator inhibitor 1 is dose dependent. FASEB Journal, 16, 147-154. doi:10.1096/fi.01-0552com

[39] Stockmann, A., Hess, S., Declerck, P., Timpl, R. and Preissner, K.T. (1993) Multimeric vitronectin. Identification and characterization of conformation-dependent selfassociation of the adhesive protein. Journal of Biological Chemistry, 268, 22874-22882.

[40] Seiffert, D. and Schleef, R.R. (1996) Two functionally distinct pools of vitronectin $(\mathrm{Vn})$ in the blood circulation: identification of a heparin-binding competent population of Vn within platelet alpha-granules. Blood, 88, 552-560.

[41] Hogasen, K., Mollnes, T.E. and Harboe, M. (1992) Heparin-binding properties of vitronectin are linked to complex formation as illustrated by in vitro polymerization and binding to the terminal complement complex. Journal of Biological Chemistry, 267, 23076-23082.

[42] Seiffert, D. and Loskutoff, D.J. (1996) Type 1 plasminogen activator inhibitor induces multimerization of plasma vitronectin. A suggested mechanism for the generation of the tissue form of vitronectin in vivo. Journal of Biological Chemistry, 271, 29644-29651. doi:10.1074/jbc.271.47.29644

[43] Podor, T.J., Shaughnessy, S.G., Blackburn, M.N. and Peterson, C.B. (2000) New insights into the size and stoichiometry of the plasminogen activator inhibitor type1. vitronectin complex. Journal of Biological Chemistry, 275, 25402-25410. doi:10.1074/jbc.M000362200

[44] Minor, K.H., Schar, C.R., Blouse, G.E., Shore, J.D., Lawrence, D.A., Schuck, P. and Peterson, C.B. (2005) A mechanism for assembly of complexes of vitronectin and plasminogen activator inhibitor-1 from sedimentation velocity analysis. Journal of Biological Chemistry, 280, 28711-28720. doi:10.1074/jbc.M500478200

[45] Balbo, A., Minor, K.H., Velikovsky, C.A., Mariuzza, R. A., Peterson, C.B. and Schuck, P. (2005) Studying multiprotein complexes by multisignal sedimentation velocity analytical ultracentrifugation. Proceedings of the $\mathrm{Na}$ tional Academy of Sciences of the USA, 102, 81-86. doi:10.1073/pnas.0408399102

[46] Nakamura, T., Tanaka, N., Higuma, N., Kazama, T., Kobayashi, I. and Yokota, S. (1996) The localization of plasminogen activator inhibitor-1 in glomerular subepithelial deposits in membranous nephropathy. Journal of the American Society of Nephrology, 7, 2434-2444.

[47] Inuzuka, S., Ueno, T., Torimura, T., Tamaki, S., Sugawara, H., Sakata, R., Kusaba, N., Sata, M., and Tanikawa, K. (1997) The significance of colocalization of plasminogen activator inhibitor-1 and vitronectin in hepatic fibrosis. Scandinavian Journal of Gastroenterology, 32, 1052-1060. doi:10.3109/00365529709011224

[48] Stoop, A.A., Lupu, F. and Pannekoek, H. (2000) Colocalization of thrombin, PAI-1, and vitronectin in the atherosclerotic vessel wall: A potential regulatory mechanism of thrombin activity by PAI-1/vitronectin complexes. Arteriosclerosis, Thrombosis, and Vascular Biology, 20, 1143-1149. doi:10.1161/01.ATV.20.4.1143

[49] Thompson, L.C., Goswami, S., Ginsberg, D.S., Day, D.E., Verhamme, I.M. and Peterson, C.B. (2011) Metals affect the structure and activity of human plasminogen activator inhibitor-1. Protein Science, 20, PMC3048421.

[50] Thompson, L.C., Goswami, S., Ginsberg, D.S., Day, D.E., Verhamme, I.M. and Peterson, C.B. (2011) Metals affect the structure and activity of human plasminogen activator inhibitor-1. I. Modulation of stability and protease inhibition. Protein Science, 20, 353-365. doi: $10.1002 /$ pro. 568

[51] Dahlback, B. and Podack, E.R. (1985) Characterization of human S protein, an inhibitor of the membrane attack complex of complement. Demonstration of a free reactive thiol group. Biochemistry, 24, 2368-2374. doi: $10.1021 / \mathrm{bi00330a036}$

[52] Zhuang, P., Blackburn, M.N. and Peterson, C.B. (1996) Characterization of the denaturation and renaturation of human plasma vitronectin. I. Biophysical characterization of protein unfolding and multimerization. Journal of Biological Chemistry, 271, 14323-14332. doi:10.1074/jbc.271.24.14323 
[53] Lynn, G.W., Heller, W.T., Mayasundari, A., Minor, K.H. and Peterson, C.B. (2005) A model for the three-dimensional structure of human plasma vitronectin from smallangle scattering measurements. Biochemistry, 44, 565574. doi:10.1021/bi048347s

[54] Preissner, K.T., Wassmuth, R. and Muller-Berghaus, G. (1985) Physicochemical characterization of human Sprotein and its function in the blood coagulation system. Biochemical Journal, 231, 349-355.

[55] Shaffer, M.C., Foley, T.P. and Barnes, D.W. (1984) Quantitation of spreading factor in human biologic fluids. Journal of Laboratory and Clinical Medicine, 103, 783791.

[56] Barnes, D.W., Silnutzer, J., See, C. and Shaffer, M. (1983) Characterization of human serum spreading factor with monoclonal antibody. Proceedings of the National Academy of Sciences of the USA, 80, 1362-1366.

[57] Edgell, C.J., McDonald, C.C. and Graham, J.B. (1983) Permanent cell line expressing human factor VIII-related antigen established by hybridization. Proceedings of the National Academy of Sciences of the USA, 80, 37343737. doi:10.1073/pnas.80.12.3734

[58] Emeis, J.J. and Edgell, C.J. (1988) Fibrinolytic properties of a human endothelial hybrid cell line (Ea.hy926). Blood, 71, 1669-1675.

[59] Podor, T.J., Peterson, C.B., Lawrence, D.A., Stefansson, S., Shaughnessy, S.G., Foulon, D.M., Butcher, M. and Weitz, J.I. (2000) Type 1 plasminogen activator inhibitor binds to fibrin via vitronectin. Journal of Biological Chemistry, 275, 19788-19794. doi:10.1074/jbc.M908079199

[60] Huang, Y., Haraguchi, M., Lawrence, D.A., Border, W.A., Yu, L. and Noble, N.A. (2003) A mutant, noninhibitory plasminogen activator inhibitor type 1 decreases matrix accumulation in experimental glomerulonephritis, Journal of Clinical Investigation, 112, 379-388.

[61] Kadler, K.E., Baldock, C., Bella, J. and Boot-Handford, R.P. (2007) Collagens at a glance. Journal of Cell Science, 120, 1955-1958. doi: $10.1242 /$ jcs. 03453

[62] Than, M.E., Henrich, S., Huber, R., Ries, A., Mann, K., Kuhn, K., Timpl, R., Bourenkov, G.P., Bartunik, H.D. and Bode, W. (2002) The 1.9-A crystal structure of the noncollagenous (NC1) domain of human placenta collagen IV shows stabilization via a novel type of covalent Met-Lys cross-link. Proceedings of the National Academy of Sciences of the USA, 99, 6607-6612. doi: $10.1073 /$ pnas.062183499

[63] Gebb, C., Hayman, E.G., Engvall, E. and Ruoslahti, E. (1986) Interaction of vitronectin with collagen. Journal of Biological Chemistry, 261, 16698-16703.

[64] Heremans, A., van der Schueren, B., de Cock, B., Paulsson, M., Cassiman, J.J., van den Berghe, H. and David, G. (1989) Matrix-associated heparan sulfate proteoglycan: Core protein-specific monoclonal antibodies decorate the pericellular matrix of connective tissue cells and the stromal side of basement membranes. Journal of Cell Biology, 109, 3199-3211. doi:10.1083/jcb.109.6.3199

[65] Hassell, J.R., Robey, P.G. Barrach, H.J., Wilczek, J. Rennard, S.I. and Martin, G.R. (1980) Isolation of a heparan sulfate-containing proteoglycan from basement membrane. Proceedings of the National Academy of Sciences of the USA, 77, 4494-4498.

[66] Fujiwara, S., Wiedemann, H., Timpl, R., Lustig, A. and Engel, J. (1984) Structure and interactions of heparan sulfate proteoglycans from a mouse tumor basement membrane. European Journal of Biochemistry, 143, 145157. doi:10.1111/j.1432-1033.1984.tb08353.x

[67] Gallagher, J.T., Lyon, M. and Steward, W.P. (1986) Structure and function of heparan sulphate proteoglycans. Biochemical Journal, 236, 313-325.

[68] Preissner, K.T. and Muller-Berghaus, G. (1987) Neutralization and binding of heparin by $\mathrm{S}$ protein/vitronectin in the inhibition of factor Xa by antithrombin III. Involvement of an inducible heparin-binding domain of $\mathrm{S}$ protein/vitronectin. Journal of Biological Chemistry, 262, 12247-12253.

[69] Zhuang, P., Chen, A.I. and Peterson, C.B. (1997) Native and multimeric vitronectin exhibit similar affinity for heparin. Differences in heparin binding properties induced upon denaturation are due to self-association into a multivalent form. Journal of Biological Chemistry, 272, 6858-6867. doi:10.1074/jbc.272.11.6858

[70] Ehrlich, H.J., Keijer, J., Preissner, K.T., Gebbink, R.K. and Pannekoek, H. (1991) Functional interaction of plasminogen activator inhibitor type 1 (PAI-1) and heparin. Biochemistry, 30, 1021-1028. doi:10.1021/bi00218a020

[71] Zhou, A., Huntington, J.A., Pannu, N.S., Carrell, R.W. and Read, R.J. (2003) How vitronectin binds PAI-1 to modulate fibrinolysis and cell migration. Nature Structural \& Molecular Biology, 10, 541-544. doi:10.1038/nsb943

[72] Blouse, G.E., Dupont, D.M., Schar, C.R., Jensen, J.K., Minor, K.H., Anagli, J.Y., Gardsvoll, H., Ploug, M., Peterson, C.B. and Andreasen, P.A. (2009) Interactions of plasminogen activator inhibitor-1 with vitronectin involve an extensive binding surface and induce mutual conformational rearrangements (dagger). Biochemistry, 48, 17231735. doi:10.1021/bi8017015

[73] Lawrence, D.A., Berkenpas, M.B., Palaniappan, S. and Ginsburg, D. (1994) Localization of vitronectin binding domain in plasminogen activator inhibitor-1. Journal of Biological Chemistry, 269, 15223-15228.

[74] Deng, G., Curriden, S. A., Wang, S., Rosenberg, S., and Loskutoff, D. J. (1996) Is plasminogen activator inhibitor-1 the molecular switch that governs urokinase receptor-mediated cell adhesion and release? Journal of Cell Biology, 134, 1563-1571. doi:10.1083/jcb.134.6.1563

[75] Seiffert, D. and Smith, J.W. (1997) The cell adhesion domain in plasma vitronectin is cryptic. Journal of Biological Chemistry, 272, 13705-13710. doi:10.1074/jbc.272.21.13705

[76] Okumura, Y., Kamikubo, Y., Curriden, S.A., Wang, J., Kiwada, T., Futaki, S., Kitagawa, K. and Loskutoff, D.J. (2002) Kinetic analysis of the interaction between vitronectin and the urokinase receptor. Journal of Biological Chemistry, 277, 9395-9404. doi:10.1074/jbc.M111225200

[77] Humphries, J.D., Byron, A. and Humphries, M.J. (2006) 
Integrin ligands at a glance. Journal of Cell Science, 119, 3901-3903. doi: 10.1242/jes.03098

[78] Aota, S., Nomizu, M. and Yamada, K.M. (1994) The short amino acid sequence Pro-His-Ser-Arg-Asn in human fibronectin enhances cell-adhesive function. Journal of Biological Chemistry, 269, 24756-24761.

[79] Kim, S., Bell, K., Mousa, S.A. and Varner, J.A. (2000) Regulation of angiogenesis in vivo by ligation of integrin alpha5beta1 with the central cell-binding domain of fibronectin. American Journal of Pathology, 156, 13451362. doi:10.1016/S0002-9440(10)65005-5

[80] Nip, J., Rabbani, S.A., Shibata, H.R. and Brodt, P. (1995) Coordinated expression of the vitronectin receptor and the urokinase-type plasminogen activator receptor in metastatic melanoma cells. Journal of Clinical Investigation, 95, 2096-2103. doi:10.1172/JCI117897

[81] Kjoller, L., Kanse, S.M., Kirkegaard, T., Rodenburg, K.W., Ronne, E., Goodman, S.L., Preissner, K.T., Ossowski, L. and Andreasen, P.A. (1997) Plasminogen activator inhibitor-1 represses integrin- and vitronectinmediated cell migration independently of its function as an inhibitor of plasminogen activation. Experimental Cell Research, 232, 420-429. doi:10.1006/excr.1997.3540

[82] Kumar, C.C. (2003) Integrin alpha v beta 3 as a therapeutic target for blocking tumor-induced angiogenesis. Current Drug Targets, 4, 123-131. doi:10.2174/1389450033346830

[83] Weidner, N., Semple, J.P., Welch, W.R. and Folkman, J. (1991) Tumor angiogenesis and metastasis - Correlation in invasive breast carcinoma. New England Journal of Medicine, 324, 1-8. doi:10.1056/NEJM199101033240101

[84] Reardon, D.A., Nabors, L.B., Stupp, R. and Mikkelsen, T. (2008) Cilengitide: An integrin-targeting arginine-glycine-aspartic acid peptide with promising activity for glioblastoma multiforme. Expert Opinion on Investigational Drugs, 17, 1225-1235. doi:10.1517/13543784.17.8.1225

[85] Wu, H., Beuerlein, G., Nie, Y., Smith, H., Lee, B.A., Hensler, M., Huse, W.D. and Watkins, J.D. (1998) Stepwise in vitro affinity maturation of Vitaxin, an alphav beta3-specific humanized mAb. Proceedings of the $\mathrm{Na}$ tional Academy of Sciences of the USA, 95, 6037-6042. doi:10.1073/pnas.95.11.6037

[86] Trikha, M., Zhou, Z., Nemeth, J.A., Chen, Q., Sharp, C., Emmell, E., Giles-Komar, J. and Nakada, M.T. (2004) CNTO 95, a fully human monoclonal antibody that inhibits alphav integrins, has antitumor and antiangiogenic activity in vivo. International Journal of Cancer, 110, 326335. doi:10.1002/ijc. 20116

[87] Sepp, N.T., Li, L.J., Lee, K.H., Brown, E.J., Caughman, S.W., Lawley, T.J. and Swerlick, R.A. (1994) Basic fibroblast growth factor increases expression of the alpha $\mathrm{V}$ beta 3 integrin complex on human microvascular endo- thelial cells. Journal of Investigative Dermatology, 103, 295-299. doi:10.1111/1523-1747.ep12394617

[88] Swerlick, R.A., Brown, E.J., Xu, Y., Lee, K.H., Manos, S. and Lawley, T.J. (1992) Expression and modulation of the vitronectin receptor on human dermal microvascular endothelial cells. Journal of Investigative Dermatology, 99, 715-722. doi:10.1111/1523-1747.ep12614207

[89] Brooks, P.C., Clark, R.A. and Cheresh, D.A. (1994) Requirement of vascular integrin alpha $\mathrm{v}$ beta 3 for angiogenesis. Science, 264, 569-571. doi:10.1126/science.7512751

[90] Friedlander, M., Brooks, P.C., Shaffer, R.W., Kincaid, C.M., Varner, J.A. and Cheresh, D.A. (1995) Definition of two angiogenic pathways by distinct alpha $\mathrm{v}$ integrins. Science, 270, 1500-1502. doi:10.1126/science.270.5241.1500

[91] Choi, S., Vilaire, G., Marcinkiewicz, C., Winkler, J.D., Bennett, J.S. and DeGrado, W.F. (2007) Small molecule inhibitors of integrin alpha2beta1. Journal of Medicinal Chemistry, 50, 5457-5462. doi:10.1021/jm070252b

[92] McCall-Culbreath, K.D. and Zutter, M.M. (2008) Collagen receptor integrins: Rising to the challenge. Current Drug Targets, 9, 139-149. doi:10.2174/138945008783502494

[93] Huai, Q., Zhou, A., Lin, L., Mazar, A.P., Parry, G.C., Callahan, J., Shaw, D.E., Furie, B., Furie, B.C. and Huang, M. (2008) Crystal structures of two human vitronectin, urokinase and urokinase receptor complexes. Nature Structural \& Molecular Biology, 15, 422-423. doi:10.1038/nsmb.1404

[94] Stefansson, S., Muhammad, S., Cheng, X.F., Battey, F.D., Strickland, D.K. and Lawrence, D.A. (1998) Plasminogen activator inhibitor-1 contains a cryptic high affinity binding site for the low density lipoprotein receptor-related protein. Journal of Biological Chemistry, 273, 63586366. doi:10.1074/jbc.273.11.6358

[95] Brown, S.L., Lundgren, C.H., Nordt, T. and Fujii, S. (1994) Stimulation of migration of human aortic smooth muscle cells by vitronectin: Implications for atherosclerosis. Cardiovascular Research, 28, 1815-1820. doi:10.1093/cvr/28.12.1815

[96] Kim, J.P., Zhang, K., Chen, J.D., Kramer, R.H. and Woodley, D.T. (1994) Vitronectin-driven human keratinocyte locomotion is mediated by the alpha $\mathrm{v}$ beta 5 integrin receptor. Journal of Biological Chemistry, 269, 26926-26932.

[97] Roca-Cusachs, P., Gauthier, N.C., Del Rio, A. and Sheetz, M.P. (2009) Clustering of alpha(5)beta(1) integrins determines adhesion strength whereas alpha(v)beta(3) and talin enable mechanotransduction. Proceedings of the $\mathrm{Na}$ tional Academy of Sciences of the USA, 106, 1624516250 . 


\section{ABBREVIATIONS}

1E9, anti-vitronectin monoclonal antibody (1E934)

ABTS,

2,2'-azino-bis(3-ethylbenzothiazoline-6-sulphonic acid)

ATCC, American Tissue Culture Collection

bFGF, basic fibroblast growth factor

BSA, bovine serum albumin

Col-IV, collagen-IV

DEAE, diethylaminoethyl

DMEM, Dulbecco's Modified Eagle Medium

DTNB, dithiobis-2-nitrobenzoic acid

ECM, extracellular matrix

EDTA, ethylenediaminetetraacetic acid

EMEM, Eagle's Minimum Essential Medium

FACS, fluorescent activated cell sorter

FBS, fetal bovine serum
GAG, glycosaminoglycan

HSPG, heparin sulfate proteoglycan

HUVEC, human umbilical vascular endothelial cell

IMAC, immobilized metal affinity chromatography

PBS, phosphate buffer saline

PAI-1, plasminogen activator inhibitor-1

PET, polyethylene terephthalate

PMA, phorbol 12-myristate13-acetate

SMB, somatomedin B

SMC, smooth muscle cell

T-AT, thrombin-antithrombin complex

TGF $\beta-1$, transforming growth factor beta type 1

uPA, urokinase type plasminogen activator

uPAR, uPA receptor

VEGF, vascular endothelial growth factor 